Illinois State University

ISU ReD: Research and eData

Theses and Dissertations

3-26-2018

\title{
The Perceptions Of Illinois State University Students Regarding Sexual Assault On Campus
}

Brittany Lee Acquaviva

Illinois State University, brittanyacquaviva@gmail.com

Follow this and additional works at: https://ir.library.illinoisstate.edu/etd

Part of the Criminology Commons, and the Criminology and Criminal Justice Commons

\section{Recommended Citation}

Acquaviva, Brittany Lee, "The Perceptions Of Illinois State University Students Regarding Sexual Assault On Campus" (2018). Theses and Dissertations. 835.

https://ir.library.illinoisstate.edu/etd/835

This Thesis is brought to you for free and open access by ISU ReD: Research and eData. It has been accepted for inclusion in Theses and Dissertations by an authorized administrator of ISU ReD: Research and eData. For more information, please contact ISUReD@ilstu.edu. 


\title{
THE PERCEPTIONS OF ILLINOIS STATE UNIVERSITY STUDENTS REGARDING
}

\author{
SEXUAL ASSAULT ON CAMPUS
}

\section{BRITTANY L. ACQUAVIVA}

\section{Pages}

The prevalence of sexual assault on college campuses is a continued epidemic within the United States. The increase of literature on this topic highlights the risk factors and perceptions that students hold on sexual assault. Previous findings have been able to aid in the creation of educational programs to be administered by universities to their students on commonly misconstrued topics within sexual assault and consent. This research adds to existing literature with its investigation on perceptions of sexual assault that Illinois State University students old. Specifically, this study looks at the beliefs and values that students hold about sexual assault, and their familiarity with campus services offered to victims of sexual assault. Results from this study indicate that students at Illinois State University conceptualize sexual assault and rape as two different entities with different levels of victimization assigned to each. Additionally, the findings suggest that the annual education that Illinois State University offers their students is ineffective when evaluating the retention students have of information present within the program. Findings from this study offer guidance and suggestions to Illinois State University in better educating their students on sexual assault and consent.

KEYWORDS: Campus sexual assault, Education, Rape culture, Rape myths, "College scene" 
THE PERCEPTIONS OF ILLINOIS STATE UNIVERSITY STUDENTS REGARDING

SEXUAL ASSAULT ON CAMPUS

BRITTANY L. ACQUAVIVA

A Thesis Submitted in Partial

Fulfillment of the Requirements

for the Degree of

MASTER OF SCIENCE

Department of Criminal Justice Sciences

ILLINOIS STATE UNIVERSITY

2018 
(C) 2018 Brittany L. Acquaviva 
THE PERCEPTIONS OF ILLINOIS STATE UNIVERSITY STUDENTS REGARDING SEXUAL ASSAULT ON CAMPUS

BRITTANY L. ACQUAVIVA

COMMITTEE MEMBERS:

Shelly Clevenger, Chair

Jason Ingram

Philip Mulvey 


\section{ACKNOWLEDGMENTS}

In loving memory of Bailey Lee Acquaviva.

B.L.A. 
ACKNOWLEDGMENTS

1

CONTENTS

TABLES

CHAPTER I: INTRODUCTION 1

Statement of the Problem 1

CHAPTER II: LITERATURE REVIEW

Defining Sexual Assault 3

$\begin{array}{ll}\text { Legal Definition of Sexual Assault } & 4\end{array}$

Sexual Assault on College Campuses $\quad 5$

$\begin{array}{ll}\text { Risk Factors } & 7\end{array}$

$\begin{array}{ll}\text { Athletic Sexual Assault } & 12\end{array}$

$\begin{array}{ll}\text { Greek Life Sexual Assault } & 14\end{array}$

$\begin{array}{ll}\text { Rape Culture } & 16\end{array}$

$\begin{array}{ll}\text { Rape Myths } & 17\end{array}$

$\begin{array}{ll}\text { Perception of Rape on Campus } & 19\end{array}$

Victim Interaction with the Criminal Justice System 20

Impact Sexual Assault has on Victims 22

Legislation in Response to Campus Sexual Assaults 24

$\begin{array}{ll}\text { Services Available for Victims } & 27\end{array}$

$\begin{array}{ll}\text { Campus services } & 29\end{array}$

$\begin{array}{ll}\text { Theoretical Framework } & 30\end{array}$ 
Instrumentation

Analysis Plan

Demographics

Themes

Consent Expectations

Defining Sexual Assault

Forms Consent Should Come in

Consent in Intimate Relationships

Taking Consent Away

Pressure to Consent

Sexual Assault and Consent Education Prior to Attending Illinois State University

Academic Sexual Assault or Consent Education

Parent/Guardian Sexual Assault or Consent Education

Defining Completed Rape Verses Attempted Rape

Attempted Rape Victimization

Differences between Sexual Assault and Rape 
$\begin{array}{ll}\text { Commonly Heard Rape Myths } & 61\end{array}$

$\begin{array}{ll}\text { Why Sexual Assault Occurs on Campus } & 62\end{array}$

$\begin{array}{ll}\text { The "College Scene" } & 62\end{array}$

The Presence of Alcohol 64

Lack of Education $\quad 66$

$\begin{array}{ll}\text { Entitlement } & 67\end{array}$

$\begin{array}{ll}\text { Prevalence of Sexual Assault at Illinois State University } & 68\end{array}$

Training on Sexual Assault and Consent while at Illinois State University 70

$\begin{array}{ll}\text { Life Skills Course } & 71\end{array}$

$\begin{array}{ll}\text { Syllabus week Education } & 72\end{array}$

Services Illinois State University Offers to Victims 73

$\begin{array}{ll}\text { CHAPTER V: DISCUSSION } & 75\end{array}$

$\begin{array}{ll}\text { Overview } & 75\end{array}$

$\begin{array}{ll}\text { Discussion of Results } & 76\end{array}$

$\begin{array}{ll}\text { Limitations } & 86\end{array}$

$\begin{array}{ll}\text { Future Research } & 88\end{array}$

Recommendations for Illinois State University $\quad 89$

REFERENCES 92

APPENDIX A: POSTER FOR SOLICITING PARTICIPANTS 98

APPENDIX B: VOLUNTARY INFORMED CONSENT FORM 99

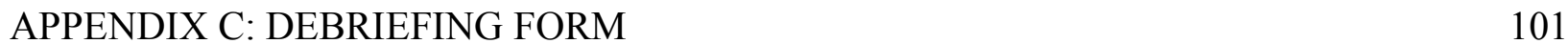

APPENDIX D: INTERVIEW GUIDE 106

$\begin{array}{ll}\text { APEENDIX E: CODEBOOK } & 108\end{array}$ 


\section{TABLES}

Table

1. Participant Characteristics

2. Demographic Frequencies
Page

43

46 


\section{CHAPTER I: INTRODUCTION}

\section{Statement of the Problem}

Women who are between the ages of 16-24 are at crucial age for possible victimization specifically with sexual assault (Aronowitz, Lambert, and Davidoff, 2012; Navarro \& Clevenger, 2017). It is argued that women who attend college are put at an even higher risk of being sexually victimized than someone who is considered a non-student (Aronowitz et al., 2012; Boyle, 2015; Armstrong, Hamilton, \& Sweeney, 2006). Rape culture and the acceptance of rape myths in society have been reported to have a parallel relationship with increase of sexual assaults. "Sexual violence is the foundation of rape culture and rape culture normalizes sexual violence" (Morczek, 2015 p.14). The acceptance of violence against women and the normalization of such acts can impact the amount of sexual assaults the occur. Media, such as television shows, songs, movies, and advertisements has contributed to women being viewed as sexual objects (Vance, Sutter, Perrin, \& Heesacker, 2015). This has been the reality in American culture for decades. American culture is focused on teaching boys and girls at a young age that those are the roles each gender is expected to take on. College students have been argued to exemplify said gender roles due to the excessive exposure to media.

With the problem of sexual assault on college campuses being highlighted in previous literature, numerous services have been made available to victims. From advocates that help victims with the daunting legal logistics to specially trained nurse examiners, the medical and criminal justice system have made steps in the right direction to give justice and control back to victims of sexual assault. However, with the existing progressive steps forward there have been negative outcomes that were not predicted. Even with reform acts put into place to protect victims such as the Clery act, universities seem to play into a reoccurring theme of not following 
full regulations of such acts. With universities seen as hunting grounds for sexual assault it is critical that they comply and are woken to how big of a problem sexual assault is.

Those who are most susceptible to becoming deviant are given at-risk educational programs to deter them from criminal behaviors, the same process can be done for sexual assault on college campuses. The purpose of this study was to explore the perceptions of college students regarding sexual assault. Specifically, this study examined knowledge, opinions and beliefs, and their familiarity with the process and services related to reporting sexual assault. In order to determine what viewpoints college students had on sexual assault, in-person semistructured interviews with college students attending Illinois State University were conducted. This methodology allowed for the researcher to ask follow-up questions and gain in-depth information from respondents as well as give students at Illinois State University an opportunity to voice their concerns and provide potential ways for the university to improve. 


\section{CHAPTER II: LITERATURE REVIEW}

\section{Defining Sexual Assault}

In defining sexual assault, many scholars are able to identify any nonconsensual sexual interactions that include any sexual contact and/or any sexual intercourse to qualify as sexual assault. When applying the legal definition to real life situations of sexual assault it is difficult for individuals to push aside certain gray areas and still consider the interactions that took place to be sexual assault (Franiuk, 2007). It has been reported that individuals are more likely to label situations as sexual assault when there is an explicit lack of consent. It has been explained that when scenarios are clear as the legal definition people compare them to they are able to draw connections easier. However, when a sexual assault involves an acquaintance and not a stranger, along with scenarios involving a lack of clear nonconsenting intercourse or sexual contact, people are hesitant and in some cases, refuse to draw the connection and classify interactions that are sexual assault as a sexual assault (Bondurant, 2001; Franiuk, 2005; Goodchilds, Zellman, Johnson, Giarrusso, 1998; Kahn, Mathie, and Torgler, 1994).

According to Mustaine and Tewksbury (2002), differing definitions of sexual assault that are used in research studies skew results creating an inconsistent rate at which sexual assaults are reported to be occurring. Using broader definitions of sexual assault allow a wide range of experiences to be included which can drive the rate of sexual assault to be more prevalent. Legal definitions of rape and sexual assault vary across jurisdictions creating synonymous definitions that manifest confusion to the public and across scholars. According to the Bureau of Justice Statistics (2016), sexual violent crimes are classified under two categories; the two categories are rape and sexual assault. Rape is defined as any forced intercourse that includes psychological and coerced actions. Also included in the definition of rape is forced or attempted sexual 
intercourse by a foreign object. Sexual assault is defined by the Bureau of Justice Statistics (2016) as attacks or attempted attacks of unwanted sexual contact that may or may not include grabbing or fondling. To the Bureau of Justice sexual assault is forced or attempted touching with the lack of any penetration. Rape can include sexual assault, however, sexual assault cannot include rape.

\section{Legal Definition of Sexual Assault}

In the Illinois Criminal Law Statues there are multiple offenses put into place to cover all sexual victimization, these include: criminal sexual assault, aggravated criminal sexual assault, predatory criminal sexual assault of a child, criminal sexual abuse, and aggravated criminal sexual abuse are the offenses one could be charged with all ranging from a class four felony to class X felonies (Illinois General Assembly, 2016). A mitigating factor that separates a sex crime into either a sexual assault or a sexual abuse case is whether or not the crime included sexual penetration or sexual conduct, as stated above. The Illinois Criminal Law Statue (2016) defines sexual conduct as:

any intentional or knowing touching or fondling by the victim or the accused, either directly or through clothing, or the sex organs, anus, or breast of the victim or the accused, or any part of the body of a child under 13 years of age, or any transfer or transmission of semen by the accused upon any part of the clothed or unclothed body of the victim, for the purpose of sexual gratification or arousal of the victim or the accused.

The offenses that cover sexual conduct are criminal sexual abuse which is a class A misdemeanor and aggravated criminal sexual abuse which is a class 2 felony. The Illinois Criminal Law Statues (2016) go on to define sexual penetration as: 
any contact however slight, between the sex orangs or anus of one person by an object, the sex organ, mouth or anus of another person, or any intrusion, however slight, or any part of the body of one person or of any animal or object into the sex organ or anus of another person, including but not limited to cunnilingus, fellatio or anal penetration. Evidence of emission of semen is not required to prove sexual penetration.

The offense that covers sexual penetration then would be criminal sexual assault which is a class 1 felony and aggravated criminal sexual assault which is a class $\mathrm{x}$ felony.

With the state statutes put in place to define and limit confusion in regards to sexual victimization, law enforcements separate have developed their own legal language to make sense of this crime which undermines the use of the statues and adds to the confusion. Authorities and scholars assert that, contrary to public belief, rape is not a sexually motivated act. It is defined within departments as a primarily violent act in which sexual relations occur as a means of expressing aggression, violence, and dominance (Hagan, 2010). The acceptance or promotion of aggression, violence, and dominance towards women is the ending results of acceptance of rape culture.

\section{Sexual Assault on College Campuses}

According to a national survey, one in five women and one in 71 men have reported experiencing a sexual assault at some point in their lives (Black, Basile, Breiding, Smith, Walters, Merrick, et al., 2011; Chang, Lin, Fowler, Yu, Jilani, Kahle, Hirsch, 2015). However, it has been reported that one in four women are sexually assaulted during their college careers. Women between the ages of 16-24 are also at a greater risk of becoming a victim compared to

those who are not within the age range (Loiselle \& Fuqua, 2007; Arnowitz et al., 2012; Chang et 
al., 2015; Armstrong et al., 2006). Traditional students who go on to achieve post-secondary education are within the age range of 16-24. This means that women who are attending college are put at a substantially high risk of becoming sexual victimized due to the two risk factors of them attending college and being within the most at risk age range.

When discussing college sexual assault, there is a correlation found with alcohol consumption. The literature finds that 50-80 percent of sexual assaults happened after the victim and perpetrator had consumed alcohol (Loiselle \& Fuqua, 2007; Armstrong et al., 2006) that alcohol consumption was highly correlated with the number of completed rapes compared to attempted rapes. Loiselle and Fuqua (2007), explains that alcohol consumption slows down an individual's reaction time including the ability to recognize situations and react to them. With a delayed reaction time, a victim's ability to fight back or engage in physical resistance is less likely to occur due to the alcohol consumed.

Also found within the literature in regards to college sexual assault, was the relationship involving miscommunication between men and women being a factor in sexual violence. The majority of communication comes from body language and conflict can occur when certain body languages are misinterpreted. Abbey, Ross, McDuffie, \& McAuslan (1996), explain that when men misinterpret a woman's sexual intention it can cause men to feel a sense of entitlement. With this feeling men tend to "take" what they feel they deserved, resulting in sexual victimization of women. The misinterpretation of friendliness as sexual intention is the most common miscommunication between male and females. About 50 percent of young men in college stated that they felt forced sex was acceptable if they had been "led on" (Abbey et al., 1996). The literature also shows that about two-thirds of college women experienced a situation 
where a man that they were socializing with misinterpreted the level of sexual interest that the women had (Addey et al., 1996).

Armstrong et al. (2006), explains that sexual assaults on college campuses can be explained by using three broad ideologies. First, the primary consequence of sexual assaults is due to precise characteristics of the perpetrator or the victim. These characteristics can include "gender roles, personality, family background, or sexual history" (Armstrong et al., 2006, p. 484). These characteristics are later noted as risk factors that multiple scholars have concluded to put women at greater risk of victimization. The second ideology examines rape culture and the rape myths that stem from it and how those influence individuals. Finally, the last ideology looks at the context in which sexual assaults happen or are promoted. Boswell and Spade (1996), proposes that "sexual assault is supported not only by a 'genetic culture surrounding and promoting rape, but also by characteristics of the 'specific settings' in which men and women interact (Armstrong et al., 2006, p. 485).

\section{Risk Factors}

Prior victimization, substance use, age and year of study, race/ethnicity, residential status, sorority membership, dating violence history, and consensual sexual experiences, are all risk factors that scholars have recorded that have an influence on whether someone is sexually victimized (Krebs, Lindquist, Warner, Fisher, \& Martin, 2007). Risk factors are not composed to victim-blame or place responsibility for the incident on the victim. They are used for prevention purposes to know who is at a greater risk of sexual victimization.

The first risk factor that has been documented is prior victimization meaning, those who have experienced a victimization before are more likely to experience victimization again than individuals who have not been victimized at all. Krebs et al. (2007), explains that the existence 
of prior victimization is the strongest predictor of one falling target to sexual assault. It was reported that women who had experienced a sexual assault prior to the academic year had a higher rate of victimization. Adolescents who have experienced a completed or attempted rape are twice as likely to experience a sequential sexual assault during their college years (Hanson $\&$ Gidycz, 1993). Individuals who experience sexual victimization have reported to experience low self-esteem, depression and poor psychological adjustment (Krebs et al., 2007). In an attempt to understand why individuals who have been victimized are at a greater risk of being revictimized, scholars have looked at substance use. Those who are experiencing low self-esteem, depression and poor psychological adjustment have been reported to attempt to self-medicate through use of drugs and/or alcohol.

Despite the memorable relationship between an individual's prior victimization and the likely hood to be re-victimized, alcohol consumption is a very prominent risk factor for sexual assault as well. Fisher, Cullen, and Turner (2000), reported that individuals who frequent drank to the excess of becoming drunk were more likely to experience a sexual assault than those who did not. Alcohol is commonly used as a sexual assault tool due to is ability to impair the physical and psychological wellbeing of an individual (Robbins \& Florsheim, 2015; Minow \& Einolf, 2009). Not only is the presence of alcohol a vital risk factor for sexual victimization but the frequency of drinking also is a risk factor. Ullman, Karabatsos, and Koss (1999), found in their National College Women's Study that victims who reported getting drunk more often also reported more severe sexual victimization than victims who did not. Overall college women are at the highest risk of alcohol-related sexual victimization than any other ethnic group (MohlerKuo, Dowdall, Koss, \& Wechsler, 2004). 
Another risk factor for sexual victimization is seen to be age and year of study during one's college career. Krebs et al. (2007), goes on to explain that freshman and sophomore women are at a higher risk of experiencing a sexual assault than upperclassmen such as juniors and seniors. Age on its own is also a risk factor seeing as women who are under 21 and under tend to not report their crimes than those who are older. This may because of the assault taking place while the victim or perpetrator was intoxicated. In 1993 out of the 10,848,090 violent offenses 91.1 percent of those fell under the rape and sexual assault by single offender category (Greenfeld, 1997). Out of the 91.1 percent only 8.0 percent were between the age of $18-20$ years old, while 31.2 percent were between the ages of 21-29 and 40.9 percent were 30 or older (Greenfeld, 1997). This shows the trend in hesitation to report potentially based on age.

The role between race/ethnicity as a risk factor for sexual victimization is not as statistically significant as the other risk factors. This is due to the lacking research including minorities who have experienced a sexual assault. However, Greenfeld (1997) reported that in 1993 victims of rape or sexual assault were just about evenly divided between Caucasians and African Americans. It was also reported that in 88 percent of forced rapes recorded, the victim and offender were of the same race (Greenfeld, 1997). This shows that sexual assault tends to be an intra-racial crime. However, when looking at more recent studies, Sinozich and Langton (2014), reported that among female college students the rate of being sexually victimized is higher for Caucasian students when compared to Hispanic individuals. Yet the rate of sexual victimization does not differ significantly when comparing Hispanic and African American students (Sinozich \& Langton, 2014).

Residency of a student is one of the risk factors that can be categorized as on-campus versus off-campus living that creates the heightened risk of sexual victimization. The results on 
residential status are conflicting in that both on-campus and off-campus have been noted as risk factors for college women. The reason for conflicting results can possibly be due to every college residency lay out being different. It was reported that the majority of sexual victimizations take place in some type of living quarters (Fisher et al., 2000). It was explained that off-campus victimization was reported more than on-campus victimization (Fisher et al., 2000). This may be because bars, social events, and student residencies tend to be off-campus. Thus, making the victims of off-campus sexual victimization still connected to the school in which the individual attends.

While there are many scholars who would agree with off-campus residency being the risk factor for victimization, on-campus living has also been reported to be just as concerning (Krebs et al., 2007). Mohler-Kuo et al. (2004), explains how students who resided in on-campus sorority houses, and dormitories were more likely be sexually assaulted. The reasoning for this was that underage students typically reside in on-campus facilities which is already a risk factor on its own. The differing research can be due to a lack of conceptualization on what is considered oncampus residency and what is considered off-campus residency.

Despite the conflicting research on on-campus compared to off-campus sexual victimization, one risk factor that scholars collectively agree on is that sorority membership is a risk factor that increases an individual's likelihood of becoming sexually victimized immensely. As sorority members tend to associate with men of fraternities more than those who are not the risk of sexual victimization heavily increases. It has been reported that women of sorority affiliation are four times more likely to be sexually assaulted than non-sorority affiliated women (Robbins \& Florsheim, 2015; Armstrong et al., 2006; Mohler-Kuo et al., 2004). Previous research goes on to explain that fraternities attract men who are predisposed to heavy drinking 
which is a predictive characteristic of sexual aggression (Robbins \& Florsheim, 2015; Krebs et al., 2007; Mohler-Kuo et al., 2004). Due to the innate relationship sororities and fraternities have with one another sorority women are exposed to men who have predictive sexually aggressive behaviors that become heightened when alcohol becomes involved. It has also been reported that inherently members of Greek organizations drink more frequently and heavily than nonmembers (Krebs et al., 2007). The question that arises when Greek affiliation is correlated with sexual victimization, is whether or not alcohol consumption is controlled for. More research needs to be done in order to answer that question to attempt to get rid of Greek women being more likely to be sexually victimized than non-Greek women.

Although it is the least researched risk factor of them all, an individual's dating violence history is worth mentioning as a risk factor for sexual victimization. According to the American College Health Association (2004), women that were involved in a physically abusive relationship with in any given year were more likely to experience sexual victimization than those who did not report being in an abusive relationship. Although not related directly it has also been found that there is overwhelmingly similar to those who were exposed to childhood domestic violence in the home as a significant risk factor for both later becoming sexually victimized and falling into a domestically violent relationship as well (Schewe, Riger, Howard, Staggs, \& Mason, 2006). According to the U.S. Department of Justice one in five women who experienced a sexual assault their perpetrator was an intimate partner (Catalano, Smith, Snyder, \& Rand, 2009).

Finally, engaging in early consensual sexual actives or being exposed to early childhood sexual assault are both risk factors for an individual to become sexually re-victimized in early adulthood as well. Fergusson, Horwood, \& Lynskey (1997), concluded that there was evidence 
to suggest that those who were exposed to early childhood sexual assault were at an increased risk for sexual risk-taking and sexual vulnerability in adolescence. These factors make young adults at risk for early onset sexual activity, unprotected intercourse, sexually transmitted infections, multiple sexual partnerships, and rape or attempted rape (Fergusson et al., 1997; Fisher et al., 2000). The increase in sexual risk-taking actions during adolescence has been argued to be caused by other third variables.

\section{Athletic Sexual Assault}

There is a relationship between college athletics and sexual assault (Ananiades, 2012). Scholars fall into two categories in regards to college athletic sexual assault (Ananiades, 2012). First, scholars would assert that athletic college sexual assault does not occur more than in the general college population. It is the media coverage that makes is appear to be occurring disproportionately (Ananiades, 2012; Trebon, 2007). Second, scholars content that the aggressive nature of athletics make athletes more prone to aggression off the field, sequentially making them then more sexually aggressive.

One explanation for the increased aggression amongst individuals involved in sports on college campuses is the idea of "macho groupthink" (Ananiades, 2012). Multiple factors such as aggression that is needed to play the sport initially, sexist language and attitudes used in the locker rooms, and the exorbitant need to proves one's manliness can all be combined and attribute to male athletes off the field aggression as well (Ananiades, 2012; Trebon, 2007). Another confounding result that scholars have used in an attempt to explain the increase of sexual assault associated with college athletics is that they tend to hold rape supportive beliefs. Specifically, contact sports as well as non-contact sports are equally likely to hold such beliefs that run parallel with rape myth acceptance beliefs (Ananiades, 2012). 
Parent (2002), also explains how sexual assault may occur in college athletics due to their own perceptions of invincibility. Individuals who go to a top university for football for their education may also be recruited by 80 other schools during the selection process. These students have been reported to then developed a heightened sense of entitlement as well as the mentality that they deserve any women they want (Parent, 2002). A study at the University of Illinois found that male individuals involved in sports teams or clubs on campus collectively encompass less than 2 percent of the total male population yet made up about 22.6 percent of the sexual assault perpetrators on campus (Ananiades, 2012). Another study was conducted at Northwestern University of Massachusetts where they reported only 3.3 percent of the population was male student-athletes, however they compiled 19 percent of the alleged sexual assault perpetrators on campus (Ananiades, 2012). The common risk factor that seems to be a reoccurring theme amongst the prevalence of sexual assault is alcohol consumption especially with college athletics. Trebon (2007), goes on to explain that athletes are more likely to engage in sexually aggressive acts after a game when the team is either out celebrating a win or mourning a loss. These acts can end in a sexual assault with the aid of alcohol.

Many individuals who are sexually victimized by a college athlete do not speak out about their assault because of the negative back lash that can come with tarnishing the reputation of the highly valued student athlete. This has been reported to occur when the perpetrator is involved with is strongly valued sport within the universities community. Weir and Brady (2003), reported that out of 168 sexual assault cases 164 involved athletes, only 22 saw their cases go to trial and of that only six resulted in a conviction. The deterrence to not report sexual assault due to the negative connotations it brings to victims is already high, but for individuals who are sexually victimized by students a part of an athletic group/sport it only grows. 


\section{Greek Life Sexual Assault}

When looking at sexual assaults on college campuses the correlation between alcohol consumption and sexual assault is significant. One half to three-quarters of sexual assaults that occur on a college campus involved alcohol, either consumed by the victim, by the perpetrator, or by both individuals (Armstrong, Hamilton, and Sweeney, 2006; Abbey et al., 1996; Sampson, 2002). In response to the relationship between alcohol and sexual assault the term "party rape" was created. Party rape specifically describes a rape that occurs either on an off-campus house or an off-campus fraternity that involves supplying women with alcohol and/or targeting them because they are intoxicated (Armstrong et al., 2006). It was reported that sexual victimization is more likely to occur off-campus than on-campus (Fisher, Cullen, \& Turner, 2000). The idea that most students reside in off-campus housing/apartments and the location of Greek housing is located off-campus as well has been argued in some universities as the explanation for this phenomenon.

Scholars across the literature consistently point out multiple risk factors and lifestyles that put women at increased risk of sexual assault, however the focus on recorded patterned problematic behaviors exhibited by likely offenders is commonly skimmed over. The culture in which fraternities thrive in is heavily acceptant of rape myths and promote a collective atmosphere of objectification and physical aggression towards women (Martin \& Hummer, 1989; Copenhaver \& Grauerholz, 1991). Copenhaver and Grauerholz (1991), found in their study of sexual assault in Greek life that acquaintance rape was most common. Meaning the victim's perpetrator as either someone they knew. It was also reported that almost half of the rapes occurred in a fraternity house and over half occurred during a fraternity function where alcohol was present (Copenhaver \& Grauerholz, 1991). 
Minow and Einolf (2009), took an interesting look on the prevalence of sexual assault and Greek life affiliation. Instead of looking at the role of fraternities they looked for any correlation between sorority membership, and whether alcohol consumption and attendance at Greek social events arbitrates the relationship. One interesting relationship occurred form this study that is worth mentioning. Attendance to social events where alcohol was present was correlated with sexual victimization amongst sorority members (Minow \& Einolf, 2009). However, when sorority members own alcohol consumption was measured the relationship between sexual victimization became obsolete (Minow \& Einolf, 2009). Based off this data it can be inferred that there is a third variable other than alcohol consumption and attendance at fraternity socials/parties that can explain the increased likelihood of sexual victimization among sorority members. It is also worth noting that those who are more active within their sorority are at a higher risk of sexual victimization than those who are in a sorority but are not as active (Kalof, 1993).

Although there is a lot of literature on sorority membership and likelihood of sexual victimization, research on sorority members falling victim to accepting rape myths is lacking. One study, however, was able to report that sorority women were significantly more likely to indorse traditional gender roles of male dominance and female submission (Kalof \& Cargill, 1991). Although the literature surrounding sorority involvement and sexual victimization is ambiguous many would argue that sorority members are at risk for sexual victimization because sorority members commonly date men who are involved in fraternities (Kalof, 1993). This argument is essentially cyclical in that the research to shifted back to fraternities being the allencompassing influencing for the increased sexual victimization on sorority women. 


\section{Rape Culture}

Rape culture is the accepting of violence directed towards a specific gender that is accepted due the normalization, justification, and rationalization of such violence. Rape culture is when "gender-based violence is securely embedded in the prevailing social fabric and taken as harmless social fact, thereby permitting violence to regenerate at an alarming rate" (Morczek, 2015). The acceptance of rape culture is heavily embedded in the acceptance of sexual assault in modern society. As the public accepts rape culture they are conforming to rape myths that accept sexual assault and place blame on victims for their own victimization.

As Morczek (2015), explained only in the year 1993 did marital rape or consensual rape with a victim's spouse become considered a crime in all 50 states. The legal shift to protect women has only been implemented for 23 years. It is a new perspective of sexual assault that many of whom are from older generations who were born before the legislature to protect married woman was implemented are still trying to understand. It is also lacking from current sexual assault research from scholars as it is a complex crime innately.

Objectification of women can be defined as seeing women as less than a human and more as an object that can be possessed. This has been looked at in connection with the increase of emotional abuse, physical abuse, and rape (Vance, Sutter, Perrin, and Heesacker, 2015). Bandura states that moral self-sanctions begin to develop early on in childhood, they guide individuals actions a certain way stopping them from going against social norms that would cause someone to experience self-blame (Vance et al., 2015). When individuals act against their self-sanctions that they have learned they develop methods to reduce the blame that they might experience, leading to the method of dehumanization as a way to cope (Vance et al., 2015). With media portraying women as objects and not as human beings in movies, TV shows, advertisements and 
commercials can lead to individuals having their views of women altered. It was reported that an individual is exposed to on average approximately 3,000 advertisements every day (Vance et al., 2015). In examining 1,988 advertisements Vance et al. (2015), found that 50 percent portrayed women as a sex object and it increased to 75 percent when looking at men's magazine's specifically. With American media culture portraying women as sex objects, rape myths flourish and have become social norms justifying individuals' action's that are negative towards women.

\section{Rape Myths}

Rape myths are the product of rape culture and the two terms are often used interchangeably in the literature. Two categories of rape within rape myths are "real rapes" and "party rapes." Brownmiller defined rape myths as "attitudes and beliefs that are generally false but are widely and persistently held, and that serve to deny and justify male sexual aggression against women" (Aronowitz, Lambert, and Davidoff, 2012). Rape culture is what defines or creates these rape myths that are used to justify crime such as sexual assault against women. A study done to measure rape myth acceptance (RMA) among first and second year college students found that 41 percent of the sample believed that if a women was raped while she was intoxicated that she was partially to blame for the assault. 63 percent of the sample agreed that if a woman makes out with a guy it is then okay for that guy to push for sex. And lastly, twentythree percent of the sample agreed that forced sex is a turn on (Aronowitz et al., 2012).

Aronowitz et al. (2012), revealed that men had a higher RMA than woman and the more sexual knowledge one had the less likely they were to accept or believe "negative social norms of peers, and the less likely the student would be to accept rape myths" (p. 179). Another explanation for males having a significantly higher RMA is the double standard that examines sexual behavior based on one gender, but cannot be applied to the other. The idea that women 
might wear certain things that put them at a greater risk for sexual assault cannot be said for the opposite sex (Aronowitz et al., 2012). This is just one aspect of what rape culture has produced and justified as a rape myth.

The question on whether a woman is actually sexually assaulted can contribute to why sexual assault is the number one underreported crime (RAINN, 2016). This often is fueled directly by rape myths themselves. The scrutiny and ridicule one receives if their assault is not considered a "real rape" in the eyes of society is sometimes worse than the actual rape itself. When believing in rape myths both men and women perceptions actively play into the existence of rape culture in different ways. When men accept rape myths it can lead to an increase of rape tendencies. For women who accept rape myths, such as what is considered a "real rape", it leads to the acceptance of victim blaming statements and placing ownership of a sexual assault on the victim (Kahlor and Eastin, 2011). A real rape has specific details within it that make it easier for society to relate to the victim. A real rape is one that involves a stranger that is the perpetrator, the act of rape was committed in a public place and there are signs that the victim resisted or became overpowered by the perpetrator that resulted in torn clothes, bloody face, body bruises (Fisher et al., 2010). Unfortunately, most sexual assaults do not happen that way causing society to question and judge. According to the National Intimate Partner and Sexual Violence Survey (2011), 51.1 percent of sexual assault victims were victimized by an intimate partner, 12.5 percent were victimized by a family member, 40.8 percent were victimized by an acquaintance, and 13.8 percent were victimized by a stranger.

In the book Unsafe in the Ivory Tower, Fisher, Daigle, and Cullen (2010), provides the example of a women named Susan Estrich who was raped. Estrich explained that she was lucky to experience the type of rape that she did. The reason for this was because no one questioned the 
legitimacy of her rape because in the eyes of the public it was a clear-cut assault. Estrich goes on to say "no one suggests that I was 'asking for it.' No one wonders, at least out loud if it was really my fault." Estrich was raped outside of her car and then afterwards her perpetrator stole her car. In Estrich's victimization her lack of consent was obvious to most people unlike many other sexual assaults, the assault happened in public, and her perpetrator was a stranger. Her assault fit perfectly into what is considered a "real rape" within today's rape culture.

This leaves a very large gray area for those who do not meet the "real rape" criteria with their victimization, creating room for criticism and judgement. The other category of rape that fits into the gray area Estrich argues is the "simple rape," a rape that is done in private with the perpetrator being someone the victim knows (Fisher et al., 2010). As Estrich argues the simple testimony of the victim saying "no" is not enough to convince others of his/her crime, only a witness to the crime or a profound amount of physical harm to which the effort of resistance cannot be challenged is when it does become enough.

\section{Perception of Rape on Campus}

The rate in which someone accepts rape myths consistently alters their perception of rape. A common thought is that some men will act in a sexually violent manner and it is the women's responsibility to avoid those men and the situation (Newcombe, Van Den Eynde, Hafner, \& Jolly, 2008). The way people interpret sexual assault can be explained by gender roles and how individuals play into their role in society. Simonson and Subich (1999) explained that acceptance of rape or sexual victimization is an extension of traditional gender roles. Gender roles that include men being expected to be masculine, dominant, powerful, and sexually aggressive and where women were expected to be fragile, submissive, passive, and quiet (Simonson \& Subich, 
1999). These same gender roles that are held within society are seen to be present on college campuses as well.

Male and female perception of rape along with their attitudes towards rape differ immensely. College men are more likely to believe that sex is the primary motivation responsible for a sexual assault occurring, whereas college women are more likely to believe power is the primary motivation (Barnett \& Field, 1977; Szymanski, Devlin, Chrisler, \& Vyse, 1993). It was also reported that college men were more likely to believe that college women who were victims of sexual assault had done something to encourage their victimization (Szymanski et al., 1993). This phenomenon has been explained by the acceptance of the rape myth that specifically, college women unconsciously desire to be raped, or the common thought process that "no" really means "yes".

Scholars have found that perpetrators who have been drinking are considered less guilty and easily sympathized with versus a sober perpetrator (Romero-Sánchez \& Megías, 2015). Women on college campuses who are sexually victimized who have also been drinking are negatively stigmatized unlike their male counterparts. This can be explained by examining gender roles and what is considered acceptable behavior for males verses females on campus. It has also been found that the mere social interaction of accepting an alcoholic drink from a man is a sign of promiscuity and desire to have sex from the women (Romero-Sánchez \& Megías, 2015).

\section{Victim Interaction with the Criminal Justice System}

The interactions involving victims of sexual assault and law enforcement have improved immensely over decades of legal reform due to civil rights movements. However, room for progress still exists in respects to better treatment of sexual assault victims. From the 50's to the 
early 70's, victims of marital sexual assault were shamed and more often than not sent away by the police because it was considered a personal problem that should be handled behind closed doors (Clevenger, 2014). Those cultural beliefs that have been established can be even seen in our law enforcement today. As pointed out before in the literature review, it took until the early 90's for martial rape to be documented as illegal across the United States (Morczek, 2015). This illustrates the slow progression of rights being given to victims of sexual assault.

Current research shows that attitudes or stereotypes that police officers hold about what they consider a "real" sexual assault reflects on how much effort of warmth is given to what they consider to be a "worthy" victim (Clevenger, 2014). This sparks an epidemic in which victims who believe they do not fit a fictitious category made up by the very people who are there to help them will not seek out help and report their victimization. Officers are so focused on building a strong case that there is an overbearing pressure to obtain physical evidence in order to do so (Clevenger, 2014). This leads to officers not wanting to take on a case where physical evidence is lacking reinforcing what is considered a "real" sexual assault.

Campus law enforcement have also been looked at in terms of their interactions with sexual assault victims due to their specific positionality as campus officers. Campus law enforcement agencies work similarly to municipal police departments however, they are considered a specialized service for the universities they reside at. The aspect that campus police agencies are both members of the criminal justice system and the universities community is what sets them apart from municipal police departments (Smith, Wilkes, \& Bouffard, 2016). Smith et al. (2016) looked at rape myth acceptance and campus officers' willingness to help victims. It was reported that case facts that involved victim's being under the influence of drugs or alcohol and victim's being inconsistent when reporting were both correlated with the myth that women 
lie about being sexually assaulted (Smith et al., 2016). The study suggested that officers who came in contact with one or both of the fact in a sexual assault case were more likely to believe that the women was lying about being sexual assault then if those facts were not included (Smith et al., 2016). It was also suggested that officers who were predisposed to believing such rape myths were reported to being more sensitive to documenting inconsistencies which later would then validate their initial belief that the victim was lying (Smith et al., 2016).

Prosecutors' on the other hand have been reported to hold the same standards. In sexual assault cases a victim's credibility is heavily weighed and has been suggested to be the determining factor on whether a case is taken or not (Frohmann, 1991). This has led to victims not feeling safe to report their assault because their credibility will be questioned by the crossexamination process by the defense if the case goes to trial (Clevenger, 2014). Victims also have been suggested to not report their sexual assaults due to the daunting fear of going through the humiliating process of telling their story multiple times and then not receiving what they consider to be justice (Konradi \& Burger, 2000). Outcomes such as victims reporting their crime and their offender not being charged, continuances being granted prolonging the sentencing of their offender, and plea bargains being given are all reported examples of justice not being served to victims of sexual assault (Clevenger, 2014). These specific examples have been reported to be strong influences for victims of sexual assault to not report their crime.

\section{Impact Sexual Assault has on Victims}

The psychological effects of being sexually victimized have been thoroughly documented through the recent decades that sexual assault research has truly emerged. It has been reported that most sexual assault victims experience posttraumatic stress disorder (PTSD) within the first couple of days to first couple of weeks following their assault (Hanson, 1990). Although scholars 
have found that symptoms diminish after a couple of months, there is still about 20 percent of those who continue to show significant life altering symptoms that result in difficulty with adjusting back to everyday living (Hanson, 1990).

Three stages of side effects have been documented with sexual victimization. Initial effects, intermediate effects, and long-term effects have been reported to coincide with sexual assault (Hanson, 1990). The initial effects of a rape consist of the feelings during the assault and few days after said assault. Most individuals who attend crisis centers or hospitals show a wide range of psychological effects because of their sexual assault. Anxiety, depression, and generalized or specific fears are just a few of the commonly recognized psychological symptoms observed with someone being sexually victimized (Hanson, 1990). Most of the effects that are visible during the initial stage of victimization role over to the intermediate stage. Finally, long term side effects of being sexually victimized are typically measured based off how well each individual was able to readjust back to daily activates years after their assault (Hanson, 1990). Initial and intermediate effects are the same with the only thing that differentiates them form one another is the amount of time one experiences the psychological symptoms. Not much conflicting data exists with the first two stages meaning almost everyone who experiences a sexual assault experiences those symptoms at some point. However, the conceptualization of long term effects is what manifests diverse findings within the literature regarding what impact sexual assault has on victims.

With PTSD being the most evident result of sexual assault, intrusive imagery can be considered the second (Burgess, 1983). Typical examples of intrusive imagery that is associated with experiencing sexual victimization are the paranoia of seeing the victims perpetrator everywhere, the reliving the traumatic events of being assaulted in the victim's mind, and the 
victim not being able to recall what happened to them immediately after their assault, but being reminded later with flashbacks or nightmares (Burgess, 1983). Intrusive imagery may occur when the individual is conscious and when they are asleep. When the individual is unconscious when such imagines are being played out in their mind is the beginning of a victim having daunting dreams and nightmares of their victimization that can cause immense stress and anxiety. Burgess (1983) goes on to list exaggerates startle response or hyper alertness, disturbance in sleep patterns, guilt about surviving or behavior employed during the assault, impairment of memory, and avoidance of actives that arouse recollection of assault as other side effects one may experiences after being sexual assaulted.

The term rape trauma syndrome (RTS) was created in 1974 by a psychiatrist and a social scientist as a result of interviews they conducted with women who all had experienced a sexual assault (McCord, 1984). The implementation of this term can be considered one of the first attempts to prove a victim's lack of consent in court. It is argued that RTS is the result of nonconsensual intercourse and that any intercourse that did involve consent would not result in RTS side effects that are parallel to side effects of PTSD (McCord, 1984). Other side effects of a life stressors such as experiencing a sexual assault sometimes trigger unhealthy coping mechanisms within victims. Some victims will participate in things such as drug or alcohol abuse in an attempt to avoid or reduce the mentioned side effects above that appear after one is sexual assaulted.

\section{Legislation in Response to Campus Sexual Assaults}

The Clery Act was the beginning of sexual assault specific legislature that was constructed to provided college students with specific rights and services if they were ever to become sexually victimized. It was implemented after the rape and murder of Jeanne Clery in her 
residence hall in 1986 (Richards \& Marcum, 2014). The Clery Act is the compellation of the Student Right-to-Know and Campus Security act of 1990 (Hayes-Smith \& Hayes-Smith, 2009; Clevenger, 2014). The Clery Act is composed of legal regulations that universities who receive public funding are bound to. The Student Right-to-Know and Campus Security Act of 1990 (that later became the Clery Act), require institutions to disclose their crime statistics publicly (HayesSmith \& Hayes-Smith, 2009). The Clery Act not only requires universities to publish their crime statistics but also to create sexual assault prevention and response policies to work coincide with the act (Hayes-Smith \& Hayes-Smith, 2009).

A downfall to the Clery Act that was not predicted is that students often feel shamed by universities and those students who are victims of sexual assault often do not report their crimes. Arguably, this is done in an attempt to save universities reputations that promotes heavy enrollment, or more specifically money that universities receive per student (Hayes-Smith \& Hayes-Smith, 2009). This practice by public universities is contributing to the problem of underreporting that sexual assault experiences. Another issue is that universities have been making information on how to report assaults, such as sexual victimization, difficult to find. This results in the lack of reporting due to students not being able to find information on school websites or simply not knowing that resources are available to victims through the Clery Act. It was reported that six out of 60 public universities had no literature on their academic websites about such resources for sexual assault victims (Hayes-Smith \& Hayes-Smith, 2009). This validates the clear lack of communication on available services for students so that universities are able to save face.

Another federal legislation that all universities are required to follow derives from Title IX which recognizes all gender inequalities that may occur on college campuses. The insurance 
of equality and safety among students is done by universities meeting several equality standards put into place to protect at risk individuals (Hayes-Smith \& Hayes-Smith, 2009). Title IX protects individuals that are victims of sexual assault and sexual harassment granting them the same education as students who were not victimized. Title IX strives to provide equal educational opportunities no matter an individual's sex at any university that receives federal financial assistance (White House Task Force, 2014).

In an attempt to reduce revictimization, Congress amended the Clery Act in 1992 and added the Campus Sexual Assault Victims' Bill of Rights (Clevenger, 2014). With both pieces of legislature cohesively working together policies, procedures, and services are required to be offered to all victims of sexual assault that occurs an individual's postsecondary education (Clevenger, 2014). The Victims' Bill of Rights ensures that both parties are treated the same throughout the student disciplinary process. They also provide victims with information on how to change their living arrangements, how to change institutions, how to contact law enforcement and assist them through the process, and to any counseling services that may be helpful (Clevenger, 2014).

Congress passed The Campus Sexual Violence Elimination Act (SaVE) in which President Obama signed into law in 2014. SaVE specifically requires domestic dating violence and stalking to be included in the annual campus crime statistics that already reported sexual assault (Clevenger, 2014). This was done due to the extended research on dating domestic violence and stalking either resulting in sexual assault or being an escalation crime to sexual assault. SaVE also requires all incoming students and new employees of universities to participate in education of bystander intervention, risk reduction, legal definitions of sexual violence and consent under state law (Clevenger, 2014). SaVE is the only national standard to 
date that universities under Title IX must adhere by. This is the first step towards standardized regulations in an attempt to hold all universities to the same standard regardless of reputation, funding, or popularity. It is the first move to show that no matter where a student decides to go to postsecondary schooling, education on prevention of sexual victimization is ubiquitous.

\section{Services Available for Victims}

The progressions in sexual assault research resulted in rape shield laws being created and implemented in almost every state by the 1980's (Clevenger, 2014). Rape shield laws were put into place to protect victims of sexual assault during the cross-examination process in courts. Rape shield laws made it illegal to bring up a victim's sexual past or any previous partners during trial. The reasoning behind this was to avoid the arguments that if a victim consented to sex before then they were more likely to have consented to sexual acts that arguably led to their sexual assault (Clevenger, 2014). Questioning the victim's credibility and ultimately victimblaming. As mentioned previously in the literature questioning one's credibility would lead to victims not wanting to come forward and report their crime. Because of rape shield laws, what once was a free for all with a victim's past sexual history is no longer fair game to use against them during trial (Clevenger, 2014).

The use of Sexual Assault Nurse Examiner's (SANE) have also developed due to the lack of professionalism sexual assault victims experienced by medical personnel. The goal of SANE's were to improve the otherwise violating and embarrassing rape kit collection process to be a sensitive and comforting process as well as advance the techniques in which evidence was collected overall to create more sound cases (Clevenger, 2014). To be recognized as a SANE one is required to go through 40-hour extensive classroom training as well as 40-96 hour clinical

training (Clevenger, 2014). During which SANE's are trained to identify rape trauma syndrome 
along with being able to handle patients who has been traumatized specific to sexual assault side effects.

The creation of crisis centers and availability to advocates are also seen as advancements for sexual assault victims. With the help of crisis centers victims were able to take the necessary steps in the right direction (Clevenger, 2014). Advocacy programs were put into place shortly after crisis centers to provide individual assistance with the legal system for sexual assault victims. Advocates have been seen to aid victims in applying for victim compensation programs, applying for order of protection, providing support and education about the trial and court processing surrounding sexual assault (Clevenger, 2014).

Clevenger (2014) explains the purpose and dynamic of sexual assault response teams (SARTs). Much like advocates, SARTs aim to assist victims through the legal system as well as the victim centered services that are available to them that they might not know about. SARTs work closely with prosecutors, other law enforcement, and victim advocates to collectively give the best care and attention to sexual assault victims (Clevenger, 2014). When a sexual assault occurs SARTs are notified and reach out to each victim within their jurisdiction. Much like the other services offered to sexual assault victims, SARTs only help individuals if they are welcomed and wanted, no service is forced upon victims in an attempt to rebuild their control in situations.

Finally, RAINN was established becoming the nation's largest anti-sexual violence organization. RAINN stands for rape, abuse and incest national network (RAINN, 2016). A national sexual assault hotline was established through the organization that offers survivors of sexual assault as well as family members services. Not only does RAINN have a phone line where victims can call to gain access to help whenever, victims are also able to chat with 
individuals working for RAINN online as well (RAINN, 2016). As most services that are offered to victims of sexual assault are reactive in nature RAINN stands out as being a proactive service as well. RAINN's communication team strives to educate the public, college campuses, the media, and entertainment industry on sexual violence (RAINN, 2016). As sexual violence tends to still be misunderstood and altered by rape myths the importance for accurate information is critical in order for the public to fully understand the crime.

\section{Campus services}

There are many services available to victims of sexual assault as well as services offered to college students who become victimized while at college. As stated above because of the Clery Act all universities who receive public funding are required by law to have a website accessible by their students in regards to sexual assault and services that are available to them. However, Hayes-Smith and Hayes-Smith (2009), explain an unexpected adverse effect such as universities were making it harder for students to find the websites on what to do if they were sexually victimized and/or that a lack of education on the existence of such websites was evident.

When looking at Illinois State University's website it was extremely easy to find an abundant amount of information and services on a wide variety of possible situations involving sexual assault. By typing in the main search bar "sexual assault" on the home page of Illinois State university numerous options for on-campus services and easy to understand information is easily accessible. Also, when looking at the Student Counseling Services home page at Illinois State University one of the 10 main tabs was sexual assault survivor services. A victim would not have to shift and search through multiple web pages in order to gain access to the information needed to help themselves. On the web tab multiple resources are listed as well as explaining what each service can offer as well as different avenues a victim may take for cope 
with their assault. The website talks about sexual assault in a gender neutral tone never inferring that sexual assault is a female crime. There is even a specific tab labeled "male survivors" for men who are sexually assaulted. Although the tab does not have as many services listed for them it would be assumed that a male victim of sexual assault would be able to use the services listed on the main sexual assault page.

Other tabs included on the sexual assault survivor services tab at the student counseling services website at Illinois State University are as follows; resources, same sex assaults, how to help a friend, Friendly Faces, alcohol and drugs, education materials, relationship violence, prevention, what can men do, and sexual assault statistics. Same-sex sexual victimization is lacking in the literature due to its complexity however, it is just as important as opposite sex sexual victimization. Same-sex sexual assault has its own tab for such victims to be able to click and gain easy access to services as well as information on the assault. The website does in depth explaining women to women assault and male to male assault giving facts and addressing misconceptions of the assaults. At the very end of the page there are specific resources as well as LGBT specific websites that victims could visit to gain additional support.

No matter the victim Illinois State university does a good job reiterating that all services for counseling and off-campus advocates or crisis centers are free and those that are not are respectfully mentioned as well. Illinois State University made sure that regardless of a victim's financial situation they would be able to gain access to the appropriate services and help that they would need.

\section{Theoretical Framework}

Social learning theory can be used in an attempt to explain how others influence and can change our own beliefs. Talking specifically with sexual assault social learning theory can be 
described as individual's beliefs changing due to the people associated and surrounding us. The acceptance of rape myths can lead to sexual assault by a group of men believing in them which sequentially influences others around them to believe them as well. With looking at all of the literature within the field of criminal justice the biggest predictor of one's criminal involvement is associated with the "number of delinquent friends" (Akers, 1990; Lilly, Cullen, and Ball, 2015; Durkin, Wolfe, \& Clark, 2005). Studies have shown that kids who are delinquent hang out with others who are delinquent because they all share the common trait of being delinquent together. In terms of fraternities and sororities, the chapters normally recruit others who are similar to themselves. If members of a chapter accept rape myths' then studies show that they will recruit others who accept rape myths' as well. The same theory can be applied to the general atmosphere of college in general. Since sexual assault occurs outside of Greek life, it can be explained that individuals in general gravitate towards those who are most like us creating groups of individuals who accept and believe in rape myths which in turn positively reinforces sexual aggression towards women. With sexual aggression being promoted towards women it has been reported that sexual assault is more likely to occur with such beliefs.

Social learning theory can also be applied to those outside of Greek life. Not everyone who attends college becomes involved in Greek life yet sexual victimization against non-Greek students continues to prevail. Humans are social beings in nature, and individuals have an unconscious need to please their peers. When heavy drinking is actively present or positively reinforced (more friends, being accepted, attracting the opposite sex) the more likely students surrounded by this behavior will engage in heavy drinking as well (Durkin, Wolfe, \& Clark, 2005). It has also been argued that deviant behavior is a behavior that is learned, being more nurture than nature based (Durkin, Wolfe, \& Clark, 2005). A specific learning process that tends 
to be linked to social learning theory is differential reinforcement. Differential reinforcement is the idea that if an individual's actions create a response of praise, acceptance, friendship, or status within their peer group those actions will then be repeated by others of that same peer group to achieve the same responses. If sexual aggression is positively viewed in a peer group or if an individual is surrounded by such beliefs then social learning theory supports the idea that the individual will become custom to accepting and viewing sexual aggression positively as well. This occurs with college student independent from Greek life as well as those with Greek affiliation.

Identity theory and male peer support theory can be seen as extensions from social learning theory. Mead and Mind (1934), explain that in identity theory, individuals have the ability to adapt and change their behavior due to interactions they have with others. Everyone has a different role based on the environment they are presently in. The way one acts in front of their grandmother is not the same as how they would act in front of their peers. Being around individuals who are accepting of rape myths and the objectification of women for satisfactory needs, leads to the prevalence of rape culture on campus and to the increase of sexual assaults. Aronowitz et al. (2012), explains that the male peer support theory can be applied specifically to males in both fraternities and college athletes. The male peer support theory explains that men abuse women because they have peers who support them in doing so and encourage actions. Being a part of a social group that encourages and supports deviant sexual behaviors towards women result in a higher rate of sexual assaults.

Routine Activity Theory is one that is widely used within literature that attempts to explain crime. Routine Activity Theory is held together by three core principles; having a motivated offender(s), the presence of a target, and the absence of a guardian or bystander 
interference (Cohen \& Felson, 1979). Despite its popularity within the field, most scholars tend to rarely apply it to sexual assault with the exception for Schwartz and Pitts. Schwartz and Pitts (1995), were the first to combine a feministic perspective to the routines activity theory. The feminist routine theory discusses the idea that women are innately more likely to fall victim to sexual crimes than men, and that there are lifestyles that college women have that attract sexual victimization more than others who do not show certain lifestyles. Very similar to risk factors that increase sexual victimization feminist routine theory points out certain lifestyles that put women in contact with men during times of vulnerability (Mustaine \& Tewksbury, 2002). Mustaine and Tewksbury (2002), explain that men assault women sexually and physically because they have the opportunity and support to. Many scholars agree that a crime cannot exist if the opportunity to commit said crime never arises (Cohen \& Felson, 1979; Mustaine \& Tewksbury, 2002). Mustaine and Tewksbury (2002), go further to explain that certain lifestyles women participate in increase their likelihood of becoming a victim of a crime compared to those who do not. It is also worth noting that the main point that separates feminist routine theory from the original routine theory is the societal norms that it applies. Society labels women as suitable targets for crime and with that comes the encouragement and acceptance of violence towards women. Lastly, society as a whole, encourages lifestyles where both men and women are present and require interactions between the both to occur (Mustaine \& Tewksbury, 2002).

For feminist routine theory, there is a heavy emphasis on the lifestyles that put women at amplified risk for sexual assault. Specifically, lifestyles that involve increased exposure to motivated offenders who positively view women as suitable victims who have minimal guardianship (Mustaine \& Tewksbury, 2002). With the feministic spin added to routine theory researchers are able to zero in on a specific offender. In recent research males have been reported 
to be more sexually aggressive than females due to the acceptance of rape myths and rape culture in the United States (Boyle, 2015; Mustaine \& Tewksbury, 2002). College campuses are a breeding ground for sexual assault where there is little to no criminal justice response. Further, because of the low penalties that men experience for sexually assaulting women the criminal justice system acting as a guardian in a larger picture is completely diminished as any sort of deterrence for perpetrators (Schwarts \& Pitts, 1995).

\section{Conclusion}

With the use of qualitative methodology, interviews with college students on their perceptions of campus sexual assault at Illinois State University were conducted. Data gathered will be able to inform other scholars and the university of specific patterns and risk factors to center future policies. With college students being at the highest risk of falling victim to sexual assault (Fisher et al., 2000) extended research on this topic would be able to create specific preventative and informative resources to students who are just entering college as well as those who are currently enrolled. Without universities fully complying by federal legislature there is always going to be the pressure for lack of reporting in fear of universities receiving back-lash or cuts to their funding or enrollment numbers. Finally, this study will help Illinois State University and other universities to create policies and programs that use a pro-active approach to college sexual assault. 


\section{CHAPTER III: METHODOLOGY}

\section{Current Focus}

Women who attend college are put at an even higher risk of being sexually victimized than someone who is considered a non-student (Aronowitz et al., 2012; Boyle, 2015; Armstrong, Hamilton, \& Sweeney, 2006). Findings presented by the Bureau of Justice Statistics support the conclusion that women ages 18-24 have higher rates of sexual victimization than any other age group as there is an increased risk for possible victimization, specifically with sexual assault (Aronowitz et al., 2012; Navarro \& Clevenger, 2017). The public has historically viewed college campuses as safe havens for students (Fisher, Daigle, \& Cullen, 2010) however, sexual assaults on college campuses have grown into an area of national concern as research has revealed cases that indicate the campus environment is not as safe as once thought (Hunter, 2005; Wilcox, Jordan, \& Prichard, 2007).

This study expands upon previous research in a number of ways. Going beyond past studies that have investigated whether or not sexual assault was occurring on college campuses in a dichotomous fashion, yes/no, this study examined college students' perceptions regarding sexual assault on campus. Second, this research explored college student's ideas about why sexual assault might be occurring on their specific campus. Lastly, in an effort to gauge student's knowledge and awareness to campus resources, this study identified how familiar college students were with the sexual assault services available to them on campus. In summation, this study gathered information on the overall perceptions that college students had about sexual assault on their campus at Illinois State University as well as investigated the familiarity of services their campus offers victims of sexual assault. 


\section{Sample And Recruitment Of Participants}

The researcher conducted semi-structured interviews with voluntary participants that were currently college students on campus as well as students who graduated within the past two years from Illinois State University. The researcher conducted 34 interviews. There was no specific age range that the researcher looked for, as long as the participant were 18 years old or older and were willing to participate. There also was no targeted number desired based on gender.

Individuals of this study were recruited through the use of purposive or judgmental/snowball sampling. Purposive sampling allows researchers to study an entire population of a limited group (Bachman \& Schutt, 2012). Nonprobability sampling such as purposive sampling, is typically used when the target population is difficult to locate or identify (Maxfield \& Babbie, 2005). The use of purposive sampling within this study allowed the researcher to gain a larger group of participants on this specific topic; comparative to the results that would have been derived from the use of a more traditional sampling method. Purposive sampling, allows researchers to deliberately chose participants based on the quality of information that they may possess and/or contribute (Tongco, 2007). Only those participants who voluntarily contacted the researcher seeking to participate in this study were interviewed. Due to the narrow nature of the research question, the researcher felt that using purposive sampling would yield the most significant results in participant participation as well as information acquisition within the interviews. The sampling strategy evolved throughout the process of conducting interviews to begin showing characteristics consistent with a snowball sample. Students who participated in the interview referred their peers to contact the researcher to 
participate. The researcher accepted all requests for participation as long as the requests were made voluntarily and by those that fit the sample requirements for this study.

Participants were obtained by voluntarily responding to posters that were placed throughout the campus (Appendix A). Posters were displayed a in Schroeder Hall on campus as well as in the Milner Library. The researcher gained prior permission to display the posters at each location on campus. The researcher was also granted permission to display posters at the local rape crisis center, Stepping Stones. Subjects contacted the researcher with inquiring on participating in an interview. Once participants were identified, they were informed of the content of study and its purpose and given the opportunity to set a date to that best worked for them to participate in an in-person interview. The average interview lasted about 30 minutes. The length of the interview was contingent upon the participant and the information he/she provided for each question.

The researcher sent the informed consent form via email before the interview to let the participants read it over on their own before the set interview day. The researcher also gave the participants the informed consent form in person for them to read once more if they wish before filling it out, singing, and returning the form to the researcher (Appendix B). The researcher was sure to express to each participant that they may at any time cease from participating in the interview without any negative consequences. Participants also were able to choose if they wanted their interview to be recorded or not. If a participant chose not to have the interview recorded, the interviewer would hand write dialogue during the interview. None of the participants opted to not have their interview recorded, therefore the researcher did not have to hand record interview dialogue during any of the interviews administered. Interviews that were tape recorded were assigned a pseudonym. A master list that matched the interviewee's actual 
names with their pseudonym's were stored and maintained separately in Dr. Clevenger's office in Schroeder 413 in a locked file cabinet; a step that was thoroughly explained to participants during the debriefing. The researcher then gave the interviewees the opportunity to ask questions before the interview began.

The researcher prearranged two locations to conduct interviews providing participants the option of which they felt most comfortable. The first option was Dr. Shelly Clevenger's office in Schroeder 413. When interviewees picked this location, Dr. Shelly Clevenger would vacate the office and provide a secure and private space for the interview to be conducted in which the door to the office was shut and locked with a sign on the door stating that there was an interview in progress. The second interview location option was the Criminal Justice Sciences Department conference room in Schroeder Hall room 441A. The conference room was available through a signup sheet that allowed participants to select what time worked best for their schedule. When a participant selected to be interviewed in the conference room, the entire room was blocked off for just the researcher and the participant with the door shut and locked; again demonstrating confidentiality and privacy to the participants who selected this interview location. Both interview locations were located on the campus of Illinois State University.

\section{Instrumentation}

A qualitative methodological approach was used in this study seeing it best fit with the objective of examining perceptions college students have in regards to sexual assault. In this study student definitions of sexual assault, perceived causes of sexual assault on campus, whether it is problematic on this campus and knowledge students had regarding services the university offers victims of sexual assault were examined. A qualitative methodological approach gives participants the ability to formulate in-depth responses to questions rather than 
pigeon holing their answers into predetermined categories (Bachman \& Schutt, 2012). The desire to gain a deeper and more in-depth understanding of college students' perceptions of sexual assault on campus the qualitative methodology seemed most suitable. With the use of in-person interviewing the participants are able to freely recount their feelings, experiences, and perceptions regarding sexual assault (Bachman \& Schutt, 2012). This style of study design provided the researcher the ability to ask follow-up questions based on the responses of the participant and gain information that may not be obtainable outside the use of interviews. The qualitative nature of this study also gave students a voice and allowed for their opinions to be heard.

The researcher was an employee of the public university which legally requires all public employees, as mandated reporters, to report any disclosure of sexual assault or domestic violence to the proper authority. If any of the participants disclosed incidents of them being sexually victimized the researcher by law had to report the incident. This was explained to all participants before the interview began to avoid any confusion or assumed break of confidentiality. As a debriefing measure, participants were given information for their local ICASA center to contact a counselor, as well as a 24 - hour hotline that they could call if they needed someone to talk to after the interview, as talking about sexual assault can cause some emotional distress (Appendix C). The interviews remained confidential through the write up process as each participant was only referred to by their assigned pseudonym.

The interviews began with the researcher asking basic demographic questions. This tactic was employed to build rapport with the interviewees and create a sense of ease with each participant so that asking about personal questions involving their perceptions of sexual assault was not difficult or uncomfortable. An interview guide (Appendix D) was used to ensure all 
major topics would be covered such as questions involving consent, education, rape myths, training received at Illinois State University, and knowledge of campus offered services for victims of sexual assault.

\section{Analysis Plan}

The researcher did not analyze any of the interviews until all of the participants who wished to participate in the study had done so. With the permission of the participants all interviews were audio recorded so that the researcher was able to better analyze the data. None of the participants requested to opt out of having their interview be recorded. The benefit of audio recording each interview is that the researcher was able to give her full attention to each participant as they expressed their perceptions of sexual assault at Illinois State University.

All interviews were transcribed verbatim by the researcher, so that reoccurring themes and patterns could be easily identified. The researcher was the only one transcribing the interviews in an attempt to add an additional layer of participant confidentiality and anonymity. In order to further strengthen the analytical capabilities of this study the researcher transferred the transcribed interviews into ATLAS.ti, a qualitative data analysis software. Following the input of all interviews into ATLAS.ti the researcher began coding for pre-determined themes

conceptualized in the study's codebook (Appendix E). However, during the process of reading through each interview, separate themes began to emerge organically. All reoccurring themes were coded as they were seen to be of utmost importance, both the original themes and the themes that developed organically. The researcher read through the interview transcriptions twice to ensure all themes were being identified.

The original themes can be separated into nine main groups. Within each main theme there were sub-themes that emerged and received a thematic code. Relevant quotes that best 
exemplified each theme were utilized to provide a voice for the participants as well as to give a better understanding of the phenomenon's that persisted within the responses on the perceptions Illinois State University students had on sexual assault. The results of this study were used to contribute to the body of academic literature and will likely appear in published scholarly articles and presentations at academic conferences. 


\section{CHAPTER IV: RESULTS}

\section{Overview}

The current study examined overall perceptions that college students at Illinois State University had about sexual assault and their familiarity with services the campus offers victims of sexual assault. Thirty-four semi-structured interviews with undergraduate students $(\mathrm{N}=12)$, graduate students $(\mathrm{N}=11)$, and recent alumni $(\mathrm{N}=11)$ of Illinois State University were completed. The full interview protocol is included in Appendix D. The contents of the results section begin with descriptive statistics of the sample that was examined. Demographic questions were gathered primarily to see if differing levels of acceptance of rape culture existed between sexes and/or educational levels. Next, nine themes that were identified are presented and discussed in order to give an in-depth understanding of the rape culture acceptance that each participant may or may not express (refer to Appendix E for the full codebook). Selected quotes are used to highlight common perceptions that were prominent within each theme.

\section{Demographics}

The following figures present sample frequencies of the study participants. In 2017, Illinois State University had 18,330 undergraduate students and 2,454 graduate students. Of those, 23 volunteered to participate in the researcher's interview, 12 undergraduate students and 11 graduate students. The remaining 11 participants were Alumni of Illinois State University who had graduated within 2 years. As shown in table 1, characteristics of all the participants in the study are presented. It is important to note that all participants were assigned a pseudonym to maintain confidentiality. Each participant's gender is identified as either male(M) or female(F) next to their pseudonym. 


\section{ILLINOIS STATE UNIVERSITY PERCEPTIONS OF SEXUAL ASSAULT}

Table 1

\section{Participant Characteristics}

\begin{tabular}{|c|c|c|c|c|}
\hline $\begin{array}{l}\text { Participants } \\
\text { Pseudonym }\end{array}$ & Age & Race & $\begin{array}{c}\text { Academic } \\
\text { Status }\end{array}$ & $\begin{array}{l}\text { Greek Life } \\
\text { Affiliation }\end{array}$ \\
\hline Lillia $(\mathrm{F})$ & 23 & Caucasian & Alum & Yes \\
\hline Oliver (M) & 24 & Caucasian & Alum & No \\
\hline April (F) & 26 & Caucasian & Alum & No \\
\hline Ann $(\mathrm{F})$ & 25 & Multicultural & Alum & No \\
\hline $\operatorname{Demi}(\mathrm{F})$ & 23 & Caucasian & Alum & Yes \\
\hline Olivia $(\mathrm{F})$ & 24 & Caucasian & Alum & Yes \\
\hline Savannah (F) & 23 & Caucasian & Alum & Yes \\
\hline Robbie (M) & 23 & Caucasian & Alum & Yes \\
\hline Candice $(\mathrm{F})$ & 23 & Caucasian & Alum & Yes \\
\hline Natalie (F) & 24 & Caucasian & Alum & No \\
\hline James (M) & 24 & Caucasian & Alum & No \\
\hline Michelle (F) & 23 & $\begin{array}{l}\text { Asian/Pacific } \\
\text { Islander }\end{array}$ & $\begin{array}{l}\text { Graduate } \\
\text { Student }\end{array}$ & No \\
\hline Charlie (F) & 24 & Caucasian & $\begin{array}{l}\text { Graduate } \\
\text { Student }\end{array}$ & No \\
\hline $\operatorname{Vinny}(\mathrm{M})$ & 23 & Caucasian & $\begin{array}{l}\text { Graduate } \\
\text { Student }\end{array}$ & No \\
\hline Catrina $(\mathrm{F})$ & 25 & Caucasian & $\begin{array}{l}\text { Graduate } \\
\text { Student }\end{array}$ & No \\
\hline Rose (F) & 26 & Caucasian & $\begin{array}{l}\text { Graduate } \\
\text { Student }\end{array}$ & No \\
\hline Andrew (M) & 31 & Caucasian & $\begin{array}{l}\text { Graduate } \\
\text { Student }\end{array}$ & No \\
\hline Duke (M) & 25 & Caucasian & $\begin{array}{l}\text { Graduate } \\
\text { Student }\end{array}$ & $\begin{array}{c}\text { No } \\
\text { (Table Cont }\end{array}$ \\
\hline
\end{tabular}




\begin{tabular}{|c|c|c|c|c|}
\hline $\begin{array}{l}\text { Participants } \\
\text { Pseudonym }\end{array}$ & Age & Race & $\begin{array}{c}\text { Academic } \\
\text { Status }\end{array}$ & $\begin{array}{l}\text { Greek Life } \\
\text { Affiliation }\end{array}$ \\
\hline Allen (M) & 24 & Caucasian & $\begin{array}{l}\text { Graduate } \\
\text { Student }\end{array}$ & No \\
\hline$T J(\mathrm{M})$ & 23 & $\begin{array}{l}\text { African } \\
\text { American }\end{array}$ & $\begin{array}{l}\text { Graduate } \\
\text { Student }\end{array}$ & No \\
\hline Evelyn (F) & 30 & Caucasian & $\begin{array}{l}\text { Graduate } \\
\text { Student }\end{array}$ & No \\
\hline $\operatorname{Melli}(\mathrm{F})$ & 23 & Caucasian & $\begin{array}{l}\text { Graduate } \\
\text { Student }\end{array}$ & No \\
\hline $\operatorname{Adam}(\mathrm{M})$ & 20 & Asian & $\begin{array}{c}\text { Undergraduate } \\
\text { Student }\end{array}$ & Yes \\
\hline $\operatorname{Jen}(\mathrm{F})$ & 21 & Hispanic & $\begin{array}{c}\text { Undergraduate } \\
\text { Student }\end{array}$ & No \\
\hline $\operatorname{Peter}(\mathrm{M})$ & 22 & Indian & $\begin{array}{c}\text { Undergraduate } \\
\text { Student }\end{array}$ & Yes \\
\hline Chuck (M) & 21 & Caucasian & $\begin{array}{c}\text { Undergraduate } \\
\text { Student }\end{array}$ & No \\
\hline Blair (F) & 20 & Caucasian & $\begin{array}{c}\text { Undergraduate } \\
\text { Student }\end{array}$ & Yes \\
\hline $\operatorname{Jack}(\mathrm{M})$ & 39 & Hispanic & $\begin{array}{c}\text { Undergraduate } \\
\text { Student }\end{array}$ & Yes \\
\hline Elizabeth $(\mathrm{F})$ & 20 & Caucasian & $\begin{array}{c}\text { Undergraduate } \\
\text { Student }\end{array}$ & Yes \\
\hline Julie (F) & 22 & Caucasian & $\begin{array}{c}\text { Undergraduate } \\
\text { Student }\end{array}$ & No \\
\hline Claire (F) & 22 & Caucasian & $\begin{array}{c}\text { Undergraduate } \\
\text { Student }\end{array}$ & No \\
\hline Marissa $(\mathrm{F})$ & 21 & Caucasian & $\begin{array}{c}\text { Undergraduate } \\
\text { Student }\end{array}$ & Yes \\
\hline Trevor (M) & 22 & Caucasian & $\begin{array}{c}\text { Undergraduate } \\
\text { Student }\end{array}$ & No \\
\hline Kavlene $(\mathrm{F})$ & 20 & Caucasian & $\begin{array}{c}\text { Undergraduate } \\
\text { Student }\end{array}$ & Yes \\
\hline
\end{tabular}

As shown in table 2, 21 percent of the sample was of minority decent which is representative of Illinois State University's student population. As of the fiscal year 2016, 20 percent of Illinois State University's enrollment was of minority decent (African American, Hispanic, Indian, Asian, Pasicifc Islander) (Illinois State University, 2016). The female participants within this 
study made up 62 percent of the sample, Illinois State University's enrollment included 56 percent of their population to be female (Illinois State University, 2016). Both racial and gender descriptive frequencies within this study are representative of the University's population. While the number of participants is low, the objective of this research was exploratory in nature to gain a greater knowledge of the perceptions of sexual assault on campus. The researcher was able to collect socially impactful information from the participants, which can prove to be of value to future researchers as well as the university in designing a new proactive and affective educational curriculum on sexual assault for their students. 


\section{ILLINOIS STATE UNIVERSITY PERCEPTIONS OF SEXUAL ASSAULT}

Table 2

Demographics frequencies

Frequency Percent

Gender

Male

13

$38 \%$

Female

$62 \%$

Race

White

$79 \%$

African American

1

$3 \%$

Multicultural

1

$3 \%$

Hispanic

2

$6 \%$

Indian

1

$3 \%$

Asian/Island Pacificer

2

$6 \%$

Class standing

Undergraduate students

12

$36 \%$

Graduate students

11

$32 \%$

Alumni

11

$32 \%$

\section{Themes}

Semi-structured interviews were conducted using an interview prompt that explored main ideas that fell within 9 overarching themes: (1) consent expectations, (2) sexual assault and consent education prior to attending Illinois State University, (3) defining completed rape verses 
an attempted rape, (4) what sexual assault looks like, (5) commonly heard rape myths, (6) why sexual assault occurs on Illinois State University's campus, (7) the prevalence of sexual assault on campus, (8) training on sexual assault and consent while attending Illinois State University, and (9) knowledge on services that Illinois State University offered victims of sexual assault. Within the 9 main themes, sub-themes were developed to gather an in-depth understanding on the perceptions of sexual assault that Illinois State University students had. A full list including definitions of these themes and sub-themes can be found in Appendix E.

\section{Consent Expectations}

Whenever the topic of sexual assault is discussed the question on what constitutes as consent shortly follows. The level of consent measures whether a sexual assault exists within the legal system as well as amongst peers. The researcher wanted to mirror this pattern by asking participants to define sexual assault with the inquiry of how participants would define consent after. This was assuming the conversation of the lack of consent would appear while participants defined sexual assault, and it did.

\section{Defining Sexual Assault}

The following responses are participant definitions of what sexual assault is. The researcher asked this question to gage the basic knowledge that students had on sexual assault. Across all responses, the most salient theme was that the lack of consent strengthened the authenticity of a sexual assault. A sexual assault occurring with a clear lack of consent verified the authenticity of the assault which sequentially also limited the amount of victim blaming and stigmatization that is felt by victims otherwise.

Michelle: "I would say it is any situation where someone was sexually violated against their consent. I think it could be anything really, I think it could be a kiss it depends" 
Oliver: "I would define sexual assault as any sexual action, whether that be touching or penetration. Any action where one party does not consent"

Duke: "Any mental or psychical harm done to a person without consent, without clear consent"

There were no significant discrepancies between genders on how participants defined sexual assault. What quickly became apparent was that not only is sexual assault a complex crime, so is constructing the classifications for consent.

\section{Forms Consent Should Come in}

Consent was not discussed in a dichotomous form, there were multiple levels and factors that students analyzed in determining if consent is given. Much of the criteria discussed on what participants believed needed to be required in order to gain consent is contingent on their perceptions of what they believe is sexual assault. This phenomenon present throughout the discussion of consent is rape culturally subjective. Interviewees were asked what forms it should be expressed in, whether consent changes in an intimate relationship, if it can be taken away, and if there are pressures to consent to sexual activity in college. The majority of participants in all three levels of the sample (undergraduate, graduate, and alumni) stated that consent needed to be a verbal only expression.

April: "I think it does need to be more of a verbal consent, um because body language and that kind of thing can be taken differently by each person"

Kaylene: "I think verbal consent would most likely be the only way to go. Because body language doesn't matter, you can't get consent with body language. I don't know I think verbally would be the only way"

Robbie: "Verbally not just like giving a sign or whatever, I know people like say that too. But yeah verbal consent I'd say"

When asked to further explain his rational for why only verbal consent should be used Robbie stated, 
“I wouldn't say body language I think that's kind of a silly way to say that it's consent. Just cause' I mean people don't know how to read each other I mean some people don't know how to pick up on those kind of signals and they could get the wrong idea"

Robbie's response best summarizes the majority of participants rationale for why verbal consent should only be exercised. Results indicate that non-verbal consent, such as body language, should not be used on its own due to the possibility of misconstrued interpretations in a vital and sensitive interaction. An exception to this rule was commonly stated in regards to intimate relationships.

\section{Consent in Intimate Relationships}

Preceding participants defining consent and what form it should come in, most of the participants, without any prompt or questioning, noted a stipulation that occurs with consent within intimate relationships. Many participants agreed in stating that there is no expectation to verbally consent to any sexual activity within an intimate relationship. Being in an agreed relationship waives the burden of gaining verbal consent. Participants went on to further explain by stating that instead, most consent is non-verbally gestured within a relationship. The nonverbal consent that is allowed to be used in place of verbal consent is justified due to the couple knowing each other and being able to read each other's non-verbal ques. These participants went further in-depth stating,

Andrew: "if you are dating your girlfriend for like 3 or 4 years or your wife for like 20 years...I mean you're not gunna hear verbal consent, it's not like they are entitled to sex, they are just not gunna look at you in the eye and say, 'I consent to have sex"'

Ann: "If you're in a relationship with someone, you don't need to verbally consent to sexual activity every time it happens. Like, there's a... it can happen non-verbally"

The expectation that individuals in intimate relationships do not have to give/get consent is a problematic cultural acceptance. Individuals in intimate relationships are not immune to misconstruing non-verbal consent. However, they are more likely to justify or minimalize actions 
that would be considered unacceptable behavior for individuals not in a relationship. As one participant described,

Melli: "The only way I would see it a little bit differently is if you are in a relationship or married and you say...I don't know, if you don't give verbal consent and you have been drinking a lot but you are already comfortable with them and maybe you didn't want to have sex [but you did anyways], the next day you aren't going to feel like oh well I didn't consent to that. I don't know it's different".

\section{Taking Consent Away}

The one aspect of consent that was unanimously agreed upon amongst all of the participants, was that consent could be taken away at any time before or during a sexual encounter. Participants also agreed that individuals in intimate relationships are also able take away their non-verbal consent. The responses on having the right to revoke someone's consent are as follows:

Natalie: "I think it has to be fluid because the range of what a sexual encounter can go from can go from so minimal to lots of different things. I think it has to be fluid and be able to change throughout the encounter"

Savannah: "let's say you were making out with a guy and all of a sudden he started to go further that would be a place where you could say 'no, I don't want to do that anymore"'

Andrew: "I think a woman can refuse sex at any point. My girlfriend does it every now and then I don't care, I'm like alright. I've told her the same things, you know not in the moment, but I'll say whatever I'll go along with my day. I think you can change your mind at any time"

An unexpected theme within these responses developed around the idea that an individual has the right to take away their consent at any time however, revoking consent must be explicitly verbal. Participants believed that individuals who want to revoke their consent have the responsibility of verbally announcing their intentions and removing themselves from the situation. In terms of intimate relationships, although the initial consent to engage in sexual activity might have been non-verbal the individual who wishes to stop engaging in sexual 
activity must verbally revoke their consent as well. This puts the entire ownership of the situation on the person who no longer wishes to engage in sexual activity.

\section{Pressure to Consent}

The last question relating to consent involved feelings of pressure to consent. The researcher asked if participants felt that there was a particular pressure to consent to sexual activity and if that was specific to being on a college campus. There were gender differences in responses with identifying what those pressures were. Most female students who responded in favor of this question explained that it was a guilty feeling that they would experience. The expectation to engage in sexual activity after a date in which a guy paid for a women's meal, or after a night out where a guy bought all of a woman's drinks, was what initiated the feeling of guilt amongst some women. It was found that this guilt was a result of female students feeling they should consent to some form of sexual activity to pay the man back for being chivalrous or for spending money on them. Other women explained that the pressure to consent was in an attempt to strengthen or "lock in" (to make a cordial friendship/relationship into an official romantic relationship) a current relationship.

Charlie: “Absolutely. An example could be, I mean it's so cliché but the typical 'come on you know you want to, or if you really like me you'd do this, or since you don't want to then clearly you don't like me or care about me' stuff like that"

Michelle: "Yeah definitely. I think there is a lot of factors that make it's hard to say no sometimes. Because I know for me personally, this is not how it should be but sometimes if you went home with a guy he already thinks that this is happening. Or he bought me food he bought me drinks...it shouldn't be that way but I can't help but sometimes feel like that, even if I don't want to"

Marissa: "I feel like when people come here they are like oh I shouldn't be a virgin I should be sleeping with this many people. Not saying that it's a thing, but some girls think that. Or they think they won't fit in if they haven't done the same thing that this other girl has done so just a standard" 
Men who responded in favor of this question explained that the pressure to consent was the result of them wanting to fit in socially amongst their peers. It should be noted that although no men reported feeling a sense of pressure to consent due to an emotional feeling of guilt or to secure a relationship, women also reported feeling a sense of pressure to consent in order to fit in socially amongst their peers. This was when the code "just want to fit in" was created. This code is unique in that it was coded in terms for explaining pressures to consent and later used to explain why sexual assault occurs on campus. Differences between responses for the presence of pressured consent were only at a gender level. For most participants the existence of pressured consent was not questionable. The responses only deviated from each other due to gendered differences in cultural expectations of sexual activity.

James: "I have definitely seen situations where people are peer pressured into having sex. And I would say I was one of them. And it's a very scary place to be in and it takes a very strong person to get out of that situation"

Vinny: "Yeah, I think so. Just based on the college life, you go into college under the assumption you're single it's going to be so much fun. If you hook up with people every weekend especially in the Greek life I know it's a big thing. I think there is definitely some preconceived beliefs about it going into college"

Jack: "Yeah, I think so. I think their peers play a big part in that. They might feel pressure to consent in certain situations when they might not want to"

Most of the participants agreed to either experiencing, witnessing, or acknowledging that pressured consent exists on campus were undergraduate students ( 83 percent) and graduate students (81 percent). This finding shows the magnitude of pressure to consent amongst men and women on Illinois State University's campus. 


\section{Sexual Assault and Consent Education Prior to Attending Illinois State University Academic Sexual Assault or Consent Education}

While most participants had a general knowledge of sexual assault and consent at the surface, the researcher inquired about past education that they may have received on these topics. The researcher asked if participants had received any high school education on the topic of sexual assault or consent prior to attending Illinois State University. This code was dichotomous in nature and was evaluated in terms of "yes" or "no". Twenty-four (70 percent) of the participants responded "no" that they had not received education in high school about sexual assault or consent. Ten (30 percent) of the participants responded "yes" that they did receive sexual assault and/or consent education prior to attending college. Although receiving education, it was further explained by participants as being generic and not talked about in detail.

Demi: "I'm pretty sure there was in sex ed. I believe we had course material on it but it was more of a general subset. I don't really remember anything though. I think it was briefly touched on"

Jen: "I took a health class freshman year [of high school] and probably touched on it, but it definitely wasn't, expanded or talked about it a lot. There wasn't a whole course on it"

Trevor: "Yes briefly, nothing that we took all too seriously as bad as that sounds. But we were told to respect other people"

It should be noted that some of the participants that answered "yes" to receiving sexual assault education explained that their education was on consent and respecting others which was offered to them in middle school but then never discussed again after that. Additionally, two individuals had received abstinence only education, as the only discussion centered around sexual activity in an academic setting. As stated above, not only did just 10 (30 percent) participants experience sexual assault and/or consent education prior to attending college, but the brief education that 
they did receive was not taken seriously by the students leaving no lasting impact on the participants that were interviewed for this study.

\section{Parent/Guardian Sexual Assault or Consent Education}

The lack of education on sexual assault being the catalyst for the continued existence of rape culture has continued to be argued by society and scholars. As explained above most participants reported that they did not receive education on sexual assault and/or consent through their schools. In an attempt to add to the existing literature, the researcher wanted to explored other possible avenues where students could have received education on this topic. The researcher asked if participants had talked with their parents or guardians about sexual assault and/or consent prior to attending a college. The results indicated that while almost 56 percent of participants stated that they had a talk with their parent's, most of the talks seemed just as generic as the high school education was. In some cases, the education received by students from their parents reaffirmed ownership of one's potential victimization. Although communication on the topic of sexual assault and consent occurred, it was in some instances detrimental to the child and/or misleading. The following responses are examples of such conversations that participants had with their parents or guardians:

Candice: "“I know high school boys, I know what boys want, don't be stupid, don't fall for it' [what participants father said] that kind of thing. It was kind of in some ways like watch out for the boys type of thing. But it was never a thing where we talked about that I would have to give consent or a direct explicit conversation about consent"

Evelyn: "But even, growing up my mom, I remember saying women shouldn't be teases and that's a bad thing to do. Not promiscuous. Well one you should put yourself in a position where someone is asking for sex. But if you do put yourself in a position you shouldn't be a tease you should give them what they want"

Adam: "Don't do anything if she is too drunk there is no point, don't do anything with that, just walk her home and call it a night" 
Julie: "It was just basically saying be careful don't get in situations where you might be...in a bad situation".

While not all participants had a talk with their parents or guardians about sexual assault and/or consent, every participant agreed that the education that they had received from their parents was more beneficial than the education that was given to them by their high schools or middle schools. Participants who did not have conversations with their parents or guardians about sexual assault and/or consent also agreed that those conversations would have been beneficial if they had received them. Rose, Trevor, and Jack's responses best summarize how the talks with their parents would have been/were more beneficial than their school education on sexual assault.

Rose: "I would say my parents was still the best education even though it was the most minimal. In terms of, not really talking about any detail what so ever but just this message of 'I'm here to listen, I'm not going to judge, and you don't have to do anything you don't feel safe doing". But that's not necessarily talking about what is consent or sexual assault"

Trevor: "Yes. More so the talk with my dad than the high school. Just respecting everyone and more specifically women"

Jack: "Yes, I think so. I think that it would have been valuable to have a conversation with a parent. Personal relationships are very important I think parents share a lot of wisdom and for me I wasn't close with my parent's, but it would be a benefit to be close with their parents and to have conversations like that."

Parental or guardian conversations on sexual assault and/or consent with their kids was evaluated by the students based on if it simply existed or not. Unlike the education received from schools, it did not matter if the talk was generic, if it occurred students expressed gratitude for it. This finding is an example of the importance of communication on sexual assault between parents or guardians and their children. Many of them did not receive education through their schools but were able to receive something on the topic from their parents which proved to be more beneficial to students. 


\section{Defining Completed Rape Verses Attempted Rape}

Fisher et al. (2000), looked at the prevalence of different types of victimization including completed rape and attempted rape in their national study of college women. The researcher wanted to take this concept a step further to see if students had different perceptions of sexual assault based on the level of victimization across both genders. In an attempt to explore this idea, participants were asked to discuss the difference between a completed rape and an attempted rape, if they believed there was any at all. Most participants differentiated a completed rape from an attempted rape by stating that a completed rape included penetration in some form. The definition of an attempted rape amongst participants was ambiguously interpreted. Kaylene, Melli, and Chuck's responses show how most of the participants differentiated between the two assaults.

Kaylene: "Completed rape would probably be obviously being rapes, there was penetration and stuff. And the other one would be that they attempted to rape someone and they got away or another person stopped them."

Melli: "When I think of rape its full on penetration, full on sex with someone [that] doesn't want to have sex or someone who hasn't consented. And attempted I would kind of think before penetration. I guess it is a hard."

Chuck: "Completed I would say obviously, having sex would be the biggest thing. But then attempted, I think anytime the guy, or the girl was able to stop it or any outside source was able to stop it either. If people saw what was going on and were able to stop it"

When asked to further explain what attempted rape would look like Chuck responded,

"It honestly can be harassment. It doesn't have to be anything major like rape, it could just be like ass grabbing"

Two prominent findings stem from these responses that were found amongst the other participants as well. The first was that attempted rape was not perceived to be as serious of a crime as a completed rape. This idea is explained further in the results section as it was coded for 
on its own under the code title "less of a victim if only attempted rape". The second finding was that not only does penetration need to be present for an assault to be considered a completed rape, but in order for an attempted rape to occur some third party needed to be present to stop the attempted rape from occurring or the victim got away. Kaylene, Peter, and Candice further explain the socially constructed requirement needed for an assault to be considered an attempted rape.

Kaylene: "Well attempted would be obviously you attempted to do it. Well okay yeah, I do. Completed rape would probably be obviously being rapes, there was penetration and stuff. And the other one would be that they attempted to rape someone, and they got away or another person stopped them"

Peter: "If a guy was being very physical with a girl and grabbing her and forcing her into a room or bed, obviously something she is not comfortable with but if she was able to get away from that situation it was an attempt. It wasn't to the point where anything worse occurred. It's kind of a grey area. It's not rape all the way but it's still not good"

Candice: "Whereas attempted rape I would say you kind of had to intent to rape or you have attempted it and the person stops it or somebody else stops it or it doesn't really get to the point to penetrative sex, but maybe other things were done. I don't know"

\section{Attempted Rape Victimization}

As participants started to construct what criteria was necessary in defining a completed rape and an attempted rape, the researcher noticed a significant theme reoccurring amongst participants' responses of both genders. The perception that attempted rape victims were seen as less of a victim than a completed rape victim developed. This perception accepts rape culture and reinforces the rape myth of what a "perfect rape victim" should look like. The code "less of a victim if attempted rape" was created to gain a holistic understanding of how prominent this theme was amongst all participants. After participants took a stance on what difference they believed a completed rape and an attempted rape had (if any), they were asked if a victim of a completed rape is different than a victim of an attempted rape. Twenty-one (62 percent) of the 
participants explained that victims of attempted rape were seen as less of a victim and carried more stigma for their victimization than individuals of a completed rape.

Robbie: "Completed one's people I guess maybe feel a little bit more sorry for the individual. Attempted I guess 'oh it didn't actually happen"”

Blair: "Yeah. I think that if you're a victim of attempted rape you're viewed as "oh it's not that bad", because they didn't actually get raped. Where as if it was completed I think people view it a little bit more seriously"

Marissa: “...Girls when they say that their friend got assaulted at this fraternity or something and they told me that the guys remarks were like 'oh she wanted it she was lying or he didn't really even toucher, she is making a bigger deal out of it than it was.' I just feel like people don't take it as serious".

When asked to define what attempted rape was participants were unable to give a concrete response, which left room for interpretation, as explained above. This room for interpretation invites for skepticism and victim-blaming into the scenario that is directed towards individuals who are victims of attempted rape. These perceptions all aid in the acceptance of rape culture.

\section{Differences between Sexual Assault and Rape}

Although in Illinois the term "rape" is not legally recognized, the researcher found it imperative to include it in the terminology used within the interview. As rape and sexual assault are commonly used synonymously, the researcher did not foresee a theme occurring from using the terms interchangeably. However, it was discovered that participants saw sexual assault and rape as two different entities with differing levels of victimization. TJ, Trevor, and Evelyn are just a few participants who defined sexual assault and rape as two different crimes.

$T J$ : "I guess rape is like you forced intercourse and then sexual assault is ... it can be all that stuff that leads up into it [penetration]"

Trevor: "In my own opinion I believe sexual assault can be verbal whereas I tend to view rape as a physical act. I don't think you can verbally rape someone, I associate it more with an action. Whereas sexual assault can be physical, verbal or both" 
Evelyn: "I see rape as a penetration of some orifice. And sexual assault can be a part of rape. But rape is a different activity. Rape is a subset of sexual assault and I think there are things that can be sexual assault and not rape. But I think if you were raped you experienced sexual assault"

This finding shows that sexual assault and rape are seen as two different terms both holding different levels or preconceived notions of what a victim may have experienced. This theme is very similar to the perceptions participants had on victims of a completed rape compared to an attempted rape. Individuals interpretation of assumed details of a crime are contingent on the initial term used to describe the crime (rape or sexual assault). If a sexual assault occurs, depending on how someone initially titles the assault will determine level of victimization and characteristics associated with that crime to be placed onto the victim.

\section{What Sexual Assault Looks Like}

As reported above the terminology initially used when discussing a sex crime will determine the level of victimization individuals associate it with. However, the researcher wanted to take it a step further and to explore possible visual characteristics that may be assumed when participants initially hear the term sexual assault. Participants were asked to describe what a sexual assault looked like to them. The researcher guided this question by asking participants what race and gender they saw the victim and offender as. The researcher wanted the first thing participants thought of, their initial idea of what an all-encompassing sexual assault looked like in their mind. Twenty-seven (79 percent) of the participants stated that the offender that they initially saw was male. No interviewee reported the offender being a woman. Twenty-eight (82 percent) of the participants stated that the victim in their minds was a female. It should be noted here, that the remaining 6 interviewees all explained that the victim could be any gender, this was not said for the offender. The remaining 6 interviewees explained that while they could see any gender be the victim of a sexual assault they always saw a man as the offender. Finally, 31 
(91 percent) of the participants stated that both the victim and the offender of the hypothetical sexual assault were white. The remaining 2 participants stated that the victim would be white however, the offender that they saw was either black or white. And the remaining last participant explained that they did not associate a specific race for the victim neither the offender.

An overwhelming majority of the participants explained that the initial imagery that they associated with the term sexual assault involved a white female victim and a white male offender. Most participants either prefaced their response or followed up their response with the justification of their knowledge that sexual assault could be the other way around (female offender and male victim). Participants were also observed to be confused on their responses on what race initially came to mind for the victim and offender. Peter, Michelle, and Vinny's responses show the hesitancy when explaining what race they associated with the victim and offender.

Peter: "Since we are talking about ISU [Illinois State University] ... I just assumed they were both white because ISU is a predominantly white institution"

Michelle: "So this is interesting, I don't know if it's because I have been surrounded by white people my whole life but... at first it was two white people, just like the generic looking guy and girl”

Vinny: "I think of a white guy. And the victim...probably a white girl I'd say.... just because being in the college setting especially ISU [Illinois State University]"

Both Peter and Vinny were able to justify their responses as for why they initially associated both the victim and offender to be white. Illinois State University is not as progressively diverse, resulting in most of the students enrolled at the university to be white. As of the fiscal year 2016, Illinois State University's total enrollment of white students made up 75 percent of their total enrollment (Illinois State University, 2016). This reoccurring response could also be the result of 
most of the participants being white, therefore responding on the race that they most identify with.

\section{Commonly Heard Rape Myths}

As mentioned numerous times throughout the results section, the acceptance of rape myths and victim blaming statements are pivotal to the existence of rape culture. Therefore, the capability for students to be able to recognize these statements is the evaluation of how progressive rape culture may be on campus. All of the participants were asked to list any rape myths or victim-blaming statements that they heard of either on campus or in general. Fifteen participants (44 percent) were unfamiliar with the terms rape myths and/or victim-blaming in their entirety. This was found within all 3 levels of the sample; undergraduate students, graduate students, and alumni students. Ten ( 83 percent) undergraduate students out of the total 12 who participated in the study, were unfamiliar with the terms victim-blaming and/or rape myths, making up the majority of those who were uninformed of such statements. One (1 percent) graduate student out of 11 and 4 (36 percent) alumni out of 11 were also unfamiliar with such terms. Interestingly, undergraduate students undergo annual training called "consent and respect" every fall semester that they are enrolled in classes at the university. Statements like the following show the lack of retention from the annual trainings or the ineffectiveness of the trainings as a whole.

Chuck: "I have never heard of that"

Blair: "Is that when the victim blames themselves?"

Robbie: "I have never heard the term rape myths"

For the participants that were unfamiliar with what rape myths or victim-blaming statements were, the researcher explained these concepts to them. Participants then clarified that 
they knew of these terms shortly after they were explained to them. The two most common rape myths that participants heard or recognized were if alcohol was involved then it is not considered a sexual assault and what someone was wearing instigated their victimization. There were no significant differences in knowledge or prevalence of certain rape myths amongst undergraduate students, graduate students, and alumni students. There also was no variance in responses in relation to gender.

\section{Why Sexual Assault Occurs on Campus}

More often when something hard to understand or comprehend occurs the question "why" always seems to follow such events. The question why sexual assault occurs or why someone would sexually assault another is brought up quite often within this subject area. Sequentially following this phenomenon, participants were asked why they believed sexual assault occurs on college campuses. This question was looked at to give the university potential problem areas that could be better addressed in future educational programs. Four strong themes emerged from participants' responses to this question. The college scene, the presence of alcohol, the lack of education, and entitlement all became reoccurring explanations for why sexual assault occurs on college campuses specifically.

\section{The "College Scene"}

The term "college scene" was used as an adjective by participants to justify or explain certain behaviors that occurred specifically on college campus. Twenty-two (65 percent) of participants referred to the "college scene" as being the holistic explanation for why sexual assault is present on college campuses. To better understand the definition of what the "college scene" is and why it is referenced in explaining why sexual assault is prevalent on college campuses, a few participant responses on this topic are as follows: 
April: "Because they're out on their own for the first time. Just coming like out of high school, not having that knowledge"

Ann: "It's also everybody's first time away from home and like there "Independent" and so they're like 'I'm going to go crazy, and I don't have to share a house with my parents anymore, let me do this"”

Michelle: "Reflecting on my own experiences and some of my friends, right at the beginning you are more trusting of people because everyone is so desperate for friends. It's like, "sure I will do these things or go to these places that I might be uncomfortable with, hanging out with these groups of people I don't really know, just because no one really has any friends yet. So maybe that could introduce people to unsavory individuals just by matter of trying to meet so many people on the weekends or through parties or whatever. For example, freshman year, this is embarrassing but if a guy yelled "oh there is a part at 300 Cherry" freshman me would have been like "oh yeah let's go". Now as an upperclassman I would be like I am not going to a place I don't know"

Participants explained how the lack of supervision from a parental figure mixed with the presence of new opportunities is what is referred to the "college scene", creates a risk factor for sexual victimization. The "college scene" creates a burning desire to fit in and be socially accepted by peers to make up for the lack of a parental presence and the absence of already established social groups formed in high school. This is where the code "just want to fit in" makes its second appearance.

Participants were asked if students at different levels of education were more likely to become sexually victimized than others. Meaning, were freshman and sophomores seen to be at a higher risk of being sexually victimized than juniors and seniors in college, and if so why. Participants explained that freshman and sophomores were more likely to experience the "college scene" at a much higher rate which promotes the desire to fit in to increase as well. This formula of entering college with the aspiration to fit in and create new social groups creates the ultimate risk factor for sexual victimization for freshman and sophomores entering college.

Natalie: "I think yeah freshman are [more likely to be sexually victimized] just because they want so badly to get into a party, or to go and hang out with upper classman. You are more willing to go along with things ... you don't want to be the one to make your 
friends leave the party, things like that. I think you are trying to find your place, so you feel more pressure to people please and it's not necessarily pleasing an offender but just everyone around you. You are trying not to rock the boat your freshman year. You are more likely to go along with something that you don't necessarily want to do"

Jack: "I think they are more likely to be sexually assaulted because the younger freshman and sophomores are still trying to figure out things, still trying to get into the bars, they aren't 21 . They don't really know who people are, so they are more willing to take risks which involve staying with people they don't know, getting extremely wasted [intoxicated], and doing things they normally wouldn't do"

Rose: "I guess in some ways [freshman and sophomores are more likely to be sexually victimized], again this network piece. They aren't going to say that they are not going to go to a party because they don't feel comfortable...I feel like they lack the assertiveness to be like 'I'm not going to put myself in those situations' and I think that comes with experience and age being an upper classman. I do feel like there are more pressures with younger people"

Participants explained how the "college scene" allows for individuals to experience new things

and be exposed to certain situations that may be foreign to some. It is only when the desire to fit in is added to the "college scene" when the potential for sexual victimization increases. As

Natalie, Jack, and Rose explained the appeal of fitting in can mute an individual's instinct to identify and remove oneself from potentially dangerous situations as well as promote unacceptable behaviors.

\section{The Presence of Alcohol}

As noted in the literature above, it is almost impossible not to mention alcohol in some fashion when talking about sexual assault on college campuses, this theme seemed to stay true for the current study. When participants were asked why sexual assault occurs on campus all 34 (100 percent) participants noted alcohol consumption being a problematic behavior that encourages sexual aggression.

Peter: "As shitty as this sounds drunk people. I wanted to say fraternity people but that specifies it. I know people who have negative interactions in fraternity's and with people who were not in fraternities as well. I think it's a common variable [alcohol] on campus" 
Trevor: "Without going into graphic detail I have had friends of both genders, who have told me their assault stories. I would say probably half of them were alcohol induced"

Allen: "Drinking, alcohol, not being able to consent, and there not being any boundaries because you are inebriated type of thing"

Although brief, Peter, Lillia, and Allen's responses open up a larger discussion on the relationship between alcohol consumption and the prevalence of sexual assault. Participants agreed that the presence of alcohol heightens the risk of someone becoming sexually victimized, but when asked why this phenomenon occurs no explanations could be given.

During the discussion pertaining to alcohol consumption, the researcher asked if consent altered at all when individuals were drinking. The researcher inquired on the idea of why a relationship between alcohol and sexual assault existed and if it was due to an additional layer of understanding consent being socially created at the college campus level when alcohol is involved. A surprising theme from participants at the undergraduate level developed from this question. Some of the undergraduate participants explained this idea that sexual activity while intoxicated was not considered sexual assault to a specific degree. An individual would need to be "blatantly drunk" in order for interactions between individuals to be labeled as a sexual assault. Six (50 percent) out of the 12 undergraduate participants freely mentioned this standard. Only 1 (9 percent) graduate student and 1 (9 percent) alumni spoke on this idea of setting a level of intoxication required for a sexual assault to potentially occur. Adam, Chuck, and, Elizabeth best summarize this idea of needing to be "blatantly drunk" within their responses.

Adam: "I guess like, if they can barely walk then they are really too drunk. If they are falling down or falling against the walls. Or if you know they are drunk, like obviously you see how much they have drank, you would know [if person is too intoxicated]"

Chuck: "If some chick is stumbling around and can't mutter any words and it happens form there and they end up hooking up, not only is it on the friends but it's on the person too" 
Elizabeth: "I think having sex while drunk you need consent, you should have consent. Depending on the level of how drunk you are, if you are not all there you could say yes and then in the morning not remember it. I think it's different depending on...I feel like it does depend the level you are on"

The standard of being "blatantly drunk" is based on outwardly observable characteristics of an individual who has consumed alcohol. Actions such as not being able to walk correctly, not being able to stand, and not being able to form coherent sentences or words, are criteria needed before sexual activity were to occur between two individuals in order for peers to label that as sexual assault. If these characteristics are either not observed by peers or transpires after sexual activity has occurred then the individual would not meet the socially constructed college standards of experiencing a sexual assault with alcohol involved.

\section{Lack of Education}

Another unanimous explanation for why sexual assault occurs, much like the presence of alcohol on college campuses, was the idea of the lack of education influencing bad behaviors. All 34 (100 percent) of the participants noted that although they could speak on sexual assault they truly did not know the logistics about it. Most of the participant's opinions and assumptions were based on personal experiences, social media, or the little education that they did receive on sexual assault. Participants explained how the lack of education on sexual assault is detrimental and aids in the presence of sexual violence on campus.

Catrina: "A lack of discussion in high school and a lot of people don't think it's a problem and a lot of people especially the incoming freshman and sophomores don't realize they are more likely to be victimized by someone they know so they think this isn't sexual assault, it was an accident, I was drunk"

Rose: "I think in terms of education, I think of something more formal. And I don't think it has to be formal, it can be more informal conversations between peers, between mentors, older students, younger students about...just speaking out"

Charlie: "I think a lot of it is a lack of knowledge. Just like girls don't know what constitutes as rape guys don't either. There's a lack of knowledge and it goes to both 
genders. How can a girl know what rape is and you blame the guy when he wasn't taught it either. Rape is definitely blameful, but at the same time people needs to be taught what the heck it is"

Catrina, Rose, and Charlie's responses show how complex sexual assault is and how the lack of education on such a complex issue can promote confusion and sometimes unknown victimization amongst individuals. Participants expressed the need for an all-encompassing list of what behaviors are considered to be sexual assault for both genders. Participants explained that this would make students aware of what actions are not acceptable therefore eliminating confusion for individuals not knowing what they did was wrong. It was also explained that this list would make individuals knowledgeable of their own victimization by eliminate the possibility for justification for certain acts because they would explicitly be listed as what constitutes as sexual assault.

\section{Entitlement}

Finally, the last justification that was mentioned by participants for why sexual assault occurs on the college campus, is the sense of entitlement that is present within current generations attending college. Twenty (58 percent) of the participants mentioned the sense of entitlement that people feel as being the catalyst for why sexual assault occurs. The explanations from Savannah, Natalie, and Oliver show the reasoning for participants' belief that entitlement has an influence on the prevalence of sexual assault.

Savannah: "I think that people are entitled to whatever they want and I think that that's our generation, they feel entitled to everything and so it's kind of like "well if I want to have sex with you then I'm going to have sex with you" and that's kind of how it is"

Natalie: "On college campuses, I think that it's entitlement. Like guys have this sense of 'ok, I took you on a date, I bought you drinks', even for some guys were like 'I was nice to you so I deserve sex'. Or be like 'I've spent all these days texting you, so I deserve sex'. I think it's just grand sense of entitlement" 
Oliver: "I think the root of college sexual assault would be entitlement. I just feel like the demographic of white male is born with this, not even born, just raised with this feeling that they are entitled to get whatever they want. So, they see a woman they find attractive and then feel like any advancement they make that girl should accept because they are who they are. And when the girl shoots them down, "no" does not mean "no" to them. And so yeah, I think entitlement it one of the leading factors or causes of sexual assault"

The sense of entitlement was never spoke of in terms of women exhibiting this sort of behavior, it was always referenced in explaining how men behave on college campuses. When asked why they believed this sense of entitlement existed, participants were unable to give an explanation other than stating that they believed it was a culturally influenced behavior. When this culturally influenced behavior is challenged, a sense of identity crisis develops within individuals and in order to avoid dealing with those emotions, individuals will attempt to reinforce the behavior they were taught which has the potential for fueling the acceptance and unawareness of sexual aggression.

\section{Prevalence of Sexual Assault at Illinois State University}

In order to gage the magnitude of the potential issue of sexual assault at Illinois State University, the researcher asked if participants thought that sexual assault was an issue. This question was also inquired to use in reference with the potential number of participants who knew of sexual assault cases at Illinois State University. Twenty-six (76 percent) participants expressed that they believed that sexual assault was an issue on campus. Participants were able to express their concern while also voicing their opinions about sexual assault.

Allen: "I think that is definitely an issue. I think that it's an issue that is not discussed and it's an issue that won't be discussed because it is an issue that won't make the university look good so they will deny any instance of it"

Julie: "I would say ISU [Illinois State University] really likes to pride itself as being a very safe campus and that things like that don't happen but unless they recognize regardless of the number any number above 0 is an issue then nothing is going to happen"

Duke: "Absolutely I think there is a sexual assault problem on this campus" 
Participants expressed that they believed that their university was not doing enough about sexual assault occurring on their campus in fear that their campus would look bad to the public. This idea was expressed amongst participants who stated that they felt like a business to the university and not like human beings who deserved to be protected. As most participants noted sexual assault is not just an issue exclusive to their college campuses however, that does not excuse them of the issue. It was mentioned that Illinois State University is just a by-product of rape culture and an example of how rape culture goes beyond just thinking or believing a certain way, it validates sexual victimization.

As a significant number of participants believed that sexual assault was a current issue on their campus, the number of participants who shared that they knew someone close to them who had been sexually victimized at Illinois State University reinforces this belief. Twenty-five (74 percent) participants shared that someone they knew had been sexually assaulted as a student at the university on campus.

Kaylene: "My roommate actually left this semester because she was raped".

Olivia: "I have heard multiple cases, like multiple. Some of friends some family, other social groups that I hung around. I think its super prevalent in the frat scene from firsthand experience [her sister was sexually assaulted at Illinois State University]"

Trevor: "Without going into graphic detail, I have had friends of both genders, who have told me their assault stories"

Over half of the participants explained how either they were a secondary or tertiary victim of sexual assault. It became a common and nonchalant response of participants knowing at least someone who had been sexually assaulted. It was talked about in a way that if you did not know of someone who was sexually assaulted then you did not know because they had not come out to share their victimization yet. 


\section{Training on Sexual Assault and Consent while at Illinois State University}

In order to better assess what Illinois State University could change, participants were asked if they received sexual assault training from the university and if they felt that the training was beneficial. Twenty-five (74 percent) participants acknowledged the training that Illinois State University had offered them. When participants were asked when they were given the training most participants were unable to give a clear answer. Most participants explained that they had taken the same course/training for a couple of years now and that they were unable to differentiate the trainings or remember when they had taken them.

Participants then went on to voice their opinions on if they felt that the training that Illinois State University had offered them was beneficial. Thirty-one (91 percent) participants expressed that they felt the training was ineffective and was not beneficial to them. Participants note their frustration with the university's course.

Andrew: "I don't. it's completely worthless, it's just another...it's just a check box or ISU [Illinois State University] administrators. If you don't know what consent and sexual assault are then you aren't gunna know form a bunch of text that people just skip through"

Michelle: "I just think the format that it is in...the nature of it is that people are just going to skip through. I don't want to say the content is not valuable, I think the way it is administered muddies people interest in it",

Trevor: "No because I didn't necessarily pick up anything as far as statistics. You just read it and regurgitate it. It was never really embedded in me, when its sent to you as a task it kind of takes away from the seriousness. It's annoying”.

The common opinion amongst participants was primarily centered around the administration of the training that Illinois State University offered their students. Participants expressed that online training on sexual assault and consent desensitizes the subject matter. It was also explained that having the training be online left room for individuals to carelessly complete the course without retaining any information. When the researcher asked the students what a better 
alternative would be to educating student on this topic, two major themes developed: a life sills course, and a syllabus week education course.

\section{Life Skills Course}

Participants expressed their aspiration for a course that would touch on multiple topics that would help students become better adults, where sexual assault would be a subset of the curriculum within this course. The course was referred to as a "life skills" course by multiple participants. They went on to explain that within this course not only would sexual assault and consent be discussed in a safe environment, but other essential life information could be included. Both campus and community resources that students could utilize during college to make their experience better would be covered within the course. Topics could include, how to file for taxes, what a $401 \mathrm{~K}$ plan is, and how to choose a life insurance policy when you get your first job out of college. Subjects that are not necessarily taught but expected to understand.

Melli: "Kind of like life skills, I would really like to see ISU [Illinois State University] do a required Life skills courses that not only deal with sexual assault but other things like how to do you laundry, I mean, I don't know just basic stuff. Just basic things that help you be a better human being, applied stuff that you should have learned in high school"

Charlie: "I know there was some sort of course when we were a freshman that teaches you how to take notes and stuff and that doesn't make any sense to me why there is a course on how to take notes and there isn't one on "your life is about to be completely different, you aren't living at home anymore, you are hours and hours away and you are on your own. This is a part of adulthood and part of adulthood is you having a voice and saying yes and no". like a life skills course but have a large portion of it be sexual assault based"

Olivia: "I think there needs to be a class. Some type of class based on the holistic person and relating to one another and basic social reciprocities"

Melli, Charlie, and Olivia's responses explain their requested life skills course and how it could better students at the university and also educate them on sexual assault. Unlike the on-line training course currently being implemented, this course would be in-person. This advocates for 
students who have questions to be able to ask and receive answers and potential resources if requested. Having an in-person educational course have the potential to also promote a sense of communal understanding on what is acceptable behavior, having peers hold each other accountable for their actions.

\section{Syllabus week Education}

The second suggestion that was offered as a better alternative to educate students on sexual assault was a brief course during syllabus week that all teachers would be required to administer to their students about sexual assault. Syllabus week refers to the first week of each semester where students learn about the expectations and planned curriculum of each class they are enrolled in. Participants further explained that after teachers discussed the class material other topics that could be covered around the idea of sexual assault would include: the myths that surround the crime, and the services that are available for students if they ever were to need them. Participants emphasized that they are already in the classroom therefore learning about sexual assault would no longer require additional effort from them. Participants explained that while in the classroom there is already an expectation for their attention, so they wouldn't be doing anything more than what was already expected of them.

Jack: "first of all I think there need to be a program for all the professors and staff here at ISU [Illinois State University] and mandate it. And once they mandate that I think it's important for them to prove that they are implementing it into the classroom every semester. Whether it be " $\mathrm{X}$ " amount of hours or something so people can hear it in one classroom, even if it's for 5 minutes, they will hear it in another and it's a good start to talk about it"

Claire: "So maybe the first week when people have classes every day, you get an assigned a specific time when you go and sit through it"

Candice: "They could have a 5 slide PowerPoint or a game during syllabus week. I just know as a student my top priority was not to finish that consent quiz. Just opening the doors for conversation is the best thing you can do" 
It was explained to the researcher that during syllabus week for both the fall and spring semester students are coming back to campus after some sort of break. This course that would be offered the first week of classes after the student's break would serve as a refresher on the standard for what is expected and acceptable behavior from students that semester. It was also explained by participants that syllabus week would be a perfect time to administer a training on sexual assault since classes are just getting started and they aren't as busy as they would be in the middle or end of the semester. Just like the life skills course, this training would be administered in-person as well, reaping the benefits discussed above.

\section{Services Illinois State University Offers to Victims}

The annual training that Illinois State University offers their students covers the services that are available to victims of sexual assault. The on-line training also outlines steps that students should take if they have ever experience a sexual assault. These steps include how to preserve evidence if applicable and who they could contact. Participants were asked if they could name any of the services that Illinois State University offers victims of sexual assault. This question was asked in an attempt to evaluate the effectiveness of the trainings that the university gives their students while also assessing the knowledge that students had about any of the services offered on campus. Although most participants stated above that the training was ineffective, the researcher wanted to know to what degree how ineffective it was. Thirty ( 88 percent) participants were unaware of any services that their campus offered for victims of sexual assault. Of the 30 participants, 22 (65 percent) participants guessed that student health services/student counseling services would offer some assistance to victims of sexual assault, but most responded with hesitancy.

TJ: "Um... man I can't even make up the top of my head. I know they are here though" 
Trevor: "If I were to ask anyone about what they would do or where they would go they couldn't even tell me the first step. I don't know anyone who knows that, there might be a few but yeah. God forbid if I was a victim of that [sexual assault] I wouldn't know the first thing to do"

Demi: "I believe they have counseling for it. I think it's counseling"

Vinny: "None specifically. I know there is the student health center and I know there are counselors on campus".

The ineffectiveness of the current training administered online by the university is followed up by the participants evaluations of the training as well as lack of retention of some of the most crucial bits of information from the training. Participants expressed that they felt that the training was ineffective and their lack of knowledge on services that their university offers is a testament to that ineffectiveness. The reasoning behind why online education may not be effective is still unknown, but what is known is that imperative information on sexual assault that is being administered online is not being retained by students at Illinois State University. 


\section{CHAPTER V: DISCUSSION}

\section{Overview}

The results of this study will add considerably to the current college campus sexual assault literature. As discussed in the literature review, there are plenty of college campus risk factors that have been identified that increased possibility for increased sexual victimization. This is the first study, known to the researcher, where the concept of the "college scene" being a risk factor for sexual victimization is discussed and evaluated by college students themselves. The purpose of this study was to explore the perceptions of college students regarding knowledge, opinions and beliefs, and their familiarity with the services offered to victims of sexual assault. In order to determine what viewpoints college students had on sexual assault, inperson semi-structured interviews with students attending Illinois State University were conducted. This methodology allowed for the researcher to ask follow-up questions and gain indepth information from participants as well as give students at Illinois State University a voice to express concerns and the opportunity to identify ways for the university to improve. Data gathered from this study will be able to inform both other scholars and the university of specific patterns and risk factors to center future policies around.

As mentioned in the literature, college students are at the highest risk of falling victim to sexual assault (Fisher et al., 2000), extended research on this topic allows for specific preventative and informative programs to be administered to students who are just entering college as well as those who are currently enrolled. Without universities fully complying to federal legislation, there will be the pressure for universities to aid in the lack of reporting in fear of their campuses receiving back-lash or cuts to their funding or enrollment numbers. This study will help Illinois State University and other universities to create policies and programs based on 
problematic perceptions gathered from this study. By addressing these perceptions discussed in the results and discussion sections, students have the opportunity to learn accurate and retainable information that simultaneously reduces the possibility of an individual being sexually victimized.

\section{Discussion of Results}

This study revealed that students at Illinois State University hold salient perceptions on sexual assault that reinforce rape myths within rape culture. The interview looked at nine overarching themes about sexual assault: (1) consent expectations, (2) sexual assault and consent education prior to attending Illinois State University, (3) defining completed rape verses an attempted rape, (4) what sexual assault looks like, (5) commonly heard rape myths, (6) why sexual assault occurs on Illinois State University's campus, (7) the prevalence of sexual assault on campus, (8) training on sexual assault and consent while attending Illinois State University, and (9) knowledge on services that Illinois State University offered victims of sexual assault. As explained in the results sections, each main theme had sub-themes and criteria that was socially constructed and clarified by participants.

The first topic that was discussed was on the topic of consent. Just as the literature review pointed out, the differing conceptualizations of what constitutes as sexual assault skews results across multiple studies due to scholars measuring different definitions (Mustaine \& Tewskbury, 2002). This same concept is seen to be present within the study with defining consent. Participants quickly noted that consent was a requirement for sexual activity to occur, however, stipulations and situational factors changed the forms and rules on consent on campus. The four sub-themes that were explored were forms consent should come in, consent in intimate relationships, taking consent away, and pressure to consent on college campus. 
A significant amount of participants (94 percent) in all three levels of the sample (undergraduate students, graduate students, and alumni students) agreed that consent should be a verbal only indication. As shown in the results section, Robbie gives a great explanation as to why this rule was unanimously agreed upon amongst the participants. The risk for potential miscommunication between individuals during an intimate and crucial interaction is partially eliminated by exercising verbal only consent. When in an intimate relationship consent plays a relaxed role where before it was just discussed as being a requirement. Participants explained that there is no expectation to consent when in an intimate relationship. This concept is problematic due to it leaving room for interpretation and creates a sense of expectation for what individuals in a relationship are supposed to do instead of what they want to do. Melli gives a great example of how non-consensual sex can occur in an intimate relationship but is not looked at as sexual assault because it was with someone they cared about. This perception directly exemplifies the rape myth that sexual assault cannot occur in relationships as well as if you consented once before with an individual than any other instance of sexual activity is assumed to be consented as well within an intimate relationship.

In terms of being able to take consent away all participants agreed that individuals have the right to do so at any point during a sexual encounter. When participants discussed pressured consent on campus, there was reported gender differences in responses. The pressure to consent did not come in a coercive manner unlike the results found in Fisher et al. (2000), it was a strong emotional feeling of guilt that female participants experienced. This guilt was a result of men paying for their date and women being expected to repay the man with some form of sexual activity. When male participants explained experiencing pressure to consent to sexual activity it was in terms of peer pressure or wanting to socially fit in. It should be noted that although no 
men reported feeling a sense of pressure to consent due to an emotional feeling of guilt or to secure a relationship, women also reported feeling a sense of pressure to consent in order to fit in socially amongst their peers. Eighty-three percent of undergraduate students and 81 percent of graduate students reported experiencing, witnessing or acknowledging that pressure to consent to sexual activity occurs on their campus. Only three (27 percent) of alumni students responded in favor of this idea. This finding may be the result of alumni students not being on Illinois State University's campus anymore which reinforces the argument that pressure to consent may be a specific phenomenon to the college campus.

The interviews then transitioned into a discussion on whether participants received education prior to attending Illinois State University. The researcher asked if participants received any academic forms of sexual assault and consent training as well as if they ever had a talk with their parents or guardians on sexual assault or consent. The lack of sexual assault education has been shown to be a precursor for the prevalence of sexual assault. Therefore, it is vital to gage the rate at which individuals are receiving sexual assault education prior to attending college. As multiple scholars have mentioned, women at the ages of 16-24 are at the highest risk of being sexually victimized (Loiselle \& Fuqua, 2007; Arnowitz et al., 2012; Chang et al., 2015; Armstrong et al., 2006). It was reported that 70 percent of participants did not receive any high school education on sexual assault or consent. Out of all the women in the study 52 percent explained that they had not received any high school education on sexual assault or consent. Women at the highest risk of falling victim to sexual violence are not receiving education at the beginning of the reported risk age range. It was reported that 56 percent of the participants received a talk from their parents or guardians on sexual assault and consent. Sixtytwo percent of participants who received a talk form their parent or guardian were female, and 38 
percent of them were male. Although women are receiving some form of talk about sexual assault and consent regardless of its authenticity, men seem to be being left out of this crucial conversation. The idea that men do not need education on this topic may be a result of the rape myth that men do not get sexual assaulted, further research would be needed draw these conclusions, but are worth mentioning.

However, education on this topic helps form what constitutes as acceptable and nonacceptable behaviors. As sexual assault does occur in both genders, men are more often seen as the offender. With the increase of education on what sexual assault is and the fallacies that have constructed rape culture that aid in victim blaming statements are discussed, the risk for sexual victimization in both men and women can be decreased. With an increase in communication on sexual assault in both an academic setting and within homes, an attempt to diminish rape culture would occur concurrently.

The third topic that was explored amongst participants, looked at potential differences in levels of victimization. The researcher used the terms completed rape and attempted rape to measure possible levels of victimization influenced by Fisher et al. (2000) national study on college women sexual assault victimization. Most participants that were asked to define what a completed rape was used similar if not the exact terminology that Fisher et al. (2000) used in defining a completed rape with including the existence of penetration to any orifice by any body part or object. When discussing what an attempted rape was most participants were in agreement that it was an attempt to rape however, the rest of their conceptualization was contingent on if there was a third-party present to stop the rape from occurring or if the victim escaped from the situation. Amongst all participants the definition of what an attempted rape constituted as was ambiguously described and left room open for subjective interpretation. 
Although the definition of what as an attempted rape was amongst participants was vague, it was noted to the researcher that participants believed that victims of an attempted rape were seen less as a victim and held more stigma than a victim of a completed rape. As noted in the results section, 62 percent of participants responded in terms of victims of an attempted rape being seen as less of a victim than a victim of a completed rape. Interestingly, of the 62 percent of participants, 71 percent were female participants and 29 percent were male participants. This finding shows that although not explicitly stated, participants at Illinois State University practiced the rape myth of what is a "real rape." As noted in the literature review, Kahlor and Eastin (2011), explain how gender differences in rape myth acceptance can result in two different outcomes. When men accept rape myths it can lead to an increase of rape tendencies. When women accept rape myths it can lead to the increase of victim blaming statements. This study shows that women were more likely to desensitize victims of attempted rape because they were lucky enough to not experience an "actual" rape.

One of the most substantial findings from this study was that participants distinctly differentiated sexual assault and rape holding different definitions and levels of victimization. Interestingly enough, Illinois does not implement the term "rape" within its legal system. As previously discussed in the literature review, the state of Illinois acknowledges sexual assault and sexual abuse as the two types of victimization, speaking on adult sex crimes specifically (Illinois General Assembly, 2016). Participants viewed sexual assault on a continuum where rape was the most extreme form of sexual assault. It was explained that a victim of a sexual assault would not automatically qualify to be a victim of rape however, a victim of a rape was automatically considered a victim of sexual assault. 
Much like the difference of victimization explained between a completed rape and an attempted rape, the same rules seemed to apply here as well. Individuals' interpretation of assumed details of a crime are contingent on the initial term used to describe the crime (rape or sexual assault). When a sexual assault occurs on college campus the word initially used (sexual assault or rape) to describe the assault will determine how peers perceive the crime. The term initially used to describe someone's victimization gets evaluated by peer's where a level of victimization and seriousness of the crime is then decided. As mentioned in the results section, this finding goes beyond just the lack of education that students are receiving on sexual assault. This finding can be seen as a byproduct of a lack of a national definition of what constitutes as sexual assault. This is also the result of each state having different legal terms and statues centering around sex crimes in general. With the terms rape and sexual assault being used interchangeably a socially constructed level of victimization has been assigned to the two as a result of the acceptance of rape myths.

Next, the participants were asked to describe what sexual assault was and their ability to list rape myths. A significant number of participants explained that when they first were asked what a sexual assault looked like they thought of a white female victim and a white male offender. Most participants expiated that Illinois State University's lack of diversity fueled their response for why they only saw a white male and female being a part of this hypothetical sexual assault. Others explained that their upbringing and lack of exposure to different racial ethnicities, is why participants automatically assumed white being the dominant race when describing what a sexual assault would look like. Although confused with their responses, participants were accurate in their perception of race associated with victims and offenders of sexual assault. 
White college females were reported to being at the highest risk of sexual victimization when compared to Hispanic college females (Sinozich \& Langton, 2014).

When examining the rate of knowledge that participants had on rape myths, the findings are concerning. Illinois State University reports that they administer an annual training that covers sexual assault and consent however, a significant number of under graduate students (83 percent) were unaware of explain identify the terms victim blaming and/or rape myths. If students don't know what statements are inappropriate and are not educated on the facts of sexual assault, these rape myths will continue to thrive and aid in the existence of rape culture and the lack of reporting due to the fear that rape culture instills in victims.

The sixth topic that was covered during the interview gave participants the opportunity to voice their opinion on why they believe sexual assault is occurring on their campus. The "college scene", the presence of alcohol, the lack of education, and entitlement all became reoccurring explanations participants expressed in terms of why sexual assault occurs on college campuses. Participants explained that the "college scene" involved the lack of supervision from a parental figure mixed with the presence of new opportunities. As already mentioned in the results section the "college scene" promotes a burning desire to fit in and be socially accepted by peers. This desire is fueled by the lack of a parental presence and the absence of already established social groups formed while in high school. The "college scene" is seen to be primarily experienced by freshman and sophomores entering post-secondary education. Much like Krebs et al. (2007), research stating that freshman and sophomores are more likely to become sexually victimized, participants from the current study seemed to agree with this concept. A hypothesis for why this phenomenon occurs may be explained with the help of further understanding of the effect the "college scene" has on students. 
Numerous scholars have reported alcohol consumption being a risk factor for an increase in sexual victimization on college campuses (Fisher, Cullen, \& Turner 2000; Ullman, Karabatsos, \& Koss, 1999; Mohler-Kuo, Dowdall, Koss, \& Wechsler, 2004), the participants responses emphasizing alcohol consumption mirror those results. All of the participants mentioned alcohol in some form, referring it back to a cause for sexual victimization on their college campus. While alcohol was a unanimous conclusion for why sexual assault occurs, participants expressed that they felt a lack of education on the topic was to blame as well. As stated many times the lack of education on sexual assault aids in the existence of accepted rape myths resulting from rape culture. The lack of education on sexual assault leads victims to justify incidents as being not rape sequentially feeding into rape culture and enabling sexually aggressive behavior to be acceptable.

The last explanation for why sexual assault occurs on college campuses stated by participants was with the ongoing sense of entitlement that this generation attending colleges exhibits. This same phenomenon was explored in Abbey et al. (1996), where the authors go on to report that 50 percent of young men in college that they studied, stated that they felt forced sex was acceptable if they had been "led on." This justification for sexual aggression can be explained by the societal acceptance of male aggression towards women indicative of rape culture. Future research could expand on the use and definition of the term entitlement on college campuses. As participants further explained how entitlement plays into the prevalence of sexual assault on college campuses the researcher noted that it mirrored results of rape culture acceptance. The researcher speculates that society tends to pride itself on being progressive therefore using the word entitlement as an explanation for why sexual assault occurs instead of accepting the presence of rape culture bolsters its progressive self-assessment. By renaming this 
phenomenon, it places blame for the existence of sexual assault at an individual level instead of at a societal level. Meaning it is an individual issue that people themselves need to address instead of being a larger issue that has been engraved within society that enables sexual assault to prosper.

The seventh topic that was discussed within the interview should be of most importance to Illinois State University. Although, never explicitly asked 74 percent of participants shared with the researcher that someone they knew had been sexually assaulted while on Illinois State University's campus. The response "we all know someone who has been sexually assaulted" became a nonchalant expression used to explain the magnitude of the issue on sexual assault. It should be reiterated here that Illinois State University is just a by-product of rape culture and an example of how rape culture goes beyond just thinking or believing a certain way, it influences sexual victimization. It should be noted here that due to the researchers utilization of a purposive sampling style that participants agreeing to be interviewed on their perceptions of sexual assault could have been a result of respondent bias as many of them knew someone who had been sexually victimized on campus.

While education on sexual assault that participants received was already discussed, the researcher inquired on the existence and value of the post-secondary education that students received from their university. As most participants reported not receiving any formal education prior to attending college, the education that the university administered is of most importance. Not only are incoming students at a greater risk of falling victim to sexual violence but their age also put them at risk as well. Education can be the catalyst for the extinction of rape culture if done properly and efficiently. Unfortunately, 91 percent of participants stated that the sexual assault and consent education that they received from Illinois State University was not beneficial 
to them. The effectiveness of the annual education that the university administered can also be evaluated based on the retained knowledge of the existence of the terms victim blaming and rape myths as previously explained in the discussion sections. Education is just a vital tool to fighting the acceptance of rape myths as the more sexual knowledge individuals possess the less likely they are to accept or believe victim blaming statements and rape myths all together (Aronowitz et al., 2012).

The final topic that was covered within the interview was on the knowledge of services that Illinois State University offers victims of sexual assault. As services on and off campus were covered in the training that the university administers to their students, ideally all students would then be aware of such services. However, 38 percent of participants had no idea that their university offered special services to victims of sexual assault. This finding can also be used to assess the evaluation of effectiveness and retention of the information given by the current sexual assault and consent course offered by the university.

As a surprise to the researcher a very unique concept was uncovered during the study. The idea of a "good guy" offender presented itself at a significant rate by participants. The "good guy" offender can be defined as a male offender of sexual assault who is labeled at the dichotomous level as being "good" by a significant amount of his peers instead of being labeled as "bad." This peer acceptance of being considered "good" protects an individual of typical scrutiny that an offender who was labeled as "bad" before a sexual assault allegation comes out. The label of being a male offender being a "good" person before the assault also promotes a colossal amount of victim blaming towards the victim. A "good guy" would be one that is liked by their peers and acquaintances, they do well academically, they are seen to be respectful of women, and in some cases a known feminist. Twenty-nine ( 85 percent) of participants spoke in 
terms of having sympathy for offenders of sexual assault who were labeled "good." This theme of a "good guy" offender runs parallel with the findings that Romero-Sánchez and Megías (2015) reported. As briefly discussed in the literature review, women are stigmatized and blamed harshly for their own victimization if they had been drinking at the time of their sexual assault. However, if a man was intoxicated when a sexual assault occurred they received sympathy from their peers. This same phenomenon was present within the current study. Participants were hesitant to place blame on a man if he was intoxicated and "came into their senses" during a sexual assault and stopped on his own will. Participants expressed that if a male offender was able to realize what he was doing was wrong and stop sexually assaulting another individual, then shouldn't not be in as much trouble as a male offender who finished out a sexual assault. An offender who stopped is considered a "good person".

\section{Limitations}

As with any study, this research is not immune to limitations and should be mentioned. The first noticeable limitation within this study involves the interview guide and the lack of pretesting. Due to time constraints, the interview guide was unable to be pre-tested however, it was approved by practitioners who work with this population at both Stepping Stones as well as the Health and Wellness Center at Illinois State University. Pre-testing an interview guide may have shed light on potential problems with questions involving misleading or leading terminology and unclear wording, resulting in potentially lost information to be gathered by the researcher. For

example, students' definitions of sexual assault and rape as two different phenomena might have been able to be caught earlier on and coded at the beginning of the research instead of towards the end. 
Another limitation is the sample size involved in this study. As noted in the demographic section of the results, Illinois State University was home to 18,330 undergraduate students and 2,454 graduate students as of 2017 (Jome, 2017). The researcher anticipated on a larger sample size however, due to time constraints the researcher had to stop accepting interviews in order to have time to transcribe and analyze data that was already gathered. Although the sample size is small it did not enable the researcher from obtaining in-depth and valuable information on the perceptions of sexual assault that students at Illinois State University had.

Respondent bias is another limitation that potentially could have altered the results of this study. It is possible that the 34 students who participated in the study possessed different perceptions and experiences involving sexual assault on campus that may have been different form the rest of the students populated at Illinois State University. It is possible that these students chose to participate because they had poor experiences with the university biasing their responses and altering the findings.

Another limitation to the study involves the ambiguous definition of sexual assault as a whole. While all states conceptualize sexual assault differently they also use different terminology. It is possible that transfer students that were at Illinois State University who participated in this interview were speaking in terms of their past location's legal definitions and terminology of what sexual assault and rape is constituted as. Like mentioned before, this limitation is a byproduct of a much larger issue resulting from a lack of a national definition on what sexual assault is.

While the listed limitations above do hinder the study's implications, the findings can serve as a foundation for future research on perceptions that college students hold about sexual assault. The researcher intends on continuing interviews with students at Illinois State University 
with a professor to expand the understanding and ongoing phenomenon's that have been addressed with this study so far. This researcher also hopes to conduct this research again at another university to compare perceptions that students may have at different geographical locations.

\section{Future Research}

There is a dearth of social science research that looks specifically at college student perceptions on sexual assault. Understanding the language utilized centered around the culture that derives from a college campus may give better analyses on the existence of rape culture and the acceptance of rape myths. Although there has been research on college women prevalence and perceptions of sexual assault, men continue to be forgotten within the discussion of sexual assault. Future research could explore male perceptions of sexual assault shedding light on potential gender discrepancies on the perceptions of sexual assault. With the identified potential differences in perceptions of sexual assault fueled by gender, educational programs and policies could target these and address them to proactively attempt to reduce the acceptance rate of rape culture.

Although there was brief discussion on criminological theories such as social learning theory, identity theory and male peer support theory, this research did not specifically test any one theory. Future studies could build off of the foundation of this research findings. Through testing of the criminological theories listed above in comparison to the findings from this study on pressured consent and the existence of the "college scene" could shed light on crucial aspects of college sexual assault and why it occurs. Through including a test of theory, the results could be more easily translatable to real world implications. Although findings of this study mirror the criminological theories mentioned that suggest peers influence the acceptance of sexual assault, 
there is no way, through this study, to conclude that any specific theory can be supported or rejected.

Another expansion to future research could involve the exploration of the differing conceptualizations of sexual assault and rape. Although Illinois does not legally recognize the term rape, it is widely known and used amongst society. This research could be used as a baseline for looking at the impact the two terms have on the level of victimization labeled for each assault as well as the socially constructed definitions of them. It would be beneficial to look at different perceptions outside of college students to see if this phenomenon still occurs or if it is confined to only college campuses. As the researcher mentioned the hope for this research is to expand it to other universities in different geographic locations to give a holistic understanding of the perceptions college students have on sexual assault.

The final recommendation for future research would center around the effectiveness and retention of trainings administered by universities. Future scholars could create an assessment tool to evaluate the effectiveness of trainings by measuring the retention of information other than what is being used currently. If universities are offering sexual assault and consent education to their students but it is being forgotten and is seen to be unbeneficial, universities should be held responsible. Trainings that fail to educate their audience on the topic at hand are essentially a waste of time and money for both the universities and the students required to take said trainings.

\section{Recommendations for Illinois State University}

The results from this study indicate a few areas of concern that the researcher would like to use as an opportunity to offer Illinois State University recommendations for bettering their annual education on sexual assault and consent. The first recommendation revolves around the 
form in which education is administered to students. The search shows that students believed the education on sexual assault and consent that Illinois State University offered them is not beneficial. The ineffectiveness of the current educational program can be evaluated by looking at the lack of retention participants had on multiple topics that the program covered. The researcher gave participants at the end of the interview the ability to voice their opinions on what they believed would be a better alternative that Illinois State University could do to better educate their students on sexual assault and consent. As reported in the results and discussion sections, participants unanimously agreed on administering the education in-person instead of having it online. Two reoccurring ideas for this education were discussed in terms of a life skills course offered by the university and/or having a set time during syllabus week to educate students on sexual assault and consent.

Another recommendation for Illinois State University to adapt is on the educational program that was mentioned to the researcher by Natalie who was an undergraduate student at the University of Illinois (U of I) and a graduate student at Illinois State University. Natalie explained to the researcher how $\mathrm{U}$ of I utilizes the sexual assault program called first year campus acquaintance rape education (FYCARE). Natalie explained to the researcher how the program was held and how impactful it was to her. $\mathrm{U}$ of I implemented this educational program FYCARE where older students taught in-person classes to lower classmen at the university. The classes were small enough to create a sense of safety and personalization to each session. Freshman would choose a time and date that the class was offered on that worked best for their schedule. This class was required to be completed by the end of the Fall semester or else students would not be able to register for classes for the Spring. This format of education not only gets freshman who are at the highest risk of becoming sexually victimized the education on sexual 
assault and consent, but it also forces upperclassmen (juniors and seniors) to remain educated on the topic as they are the teachers of these classes. It was explained that students who were majoring in counseling or education would typically be the ones to volunteer to administer these classes. However, it encourages the promotion of learning about sexual assault and consent in a modern and progressive fashion that is tailored to the generation of students attending college.

The researcher understands the complications and time that comes with revamping the way a particular university wide educational program is administered, and these critiques are only recommendations for the university. It should be noted here that the researcher wanted to acknowledge the current programs that Illinois State University just start this academic year of 2017. Starting in the fall semester of 2017, Students Ending Rape Culture (SERC) was implemented on campus. The program is ran by Dr. Shelly Clevenger who specializes in research and education on the topic of sexual assault. The goal of SERC is to help students gain momentum in understanding and identifying rape myths by educating students on them. The second program that more recently began is held by the local rape crisis center Stepping Stones. Stepping Stones implemented a survivor support groups in the spring semester in 2018 on Illinois State University's campus. The group allows for a safe space were victims could come together and offer support for each other while also sharing their stories, all under the supervision of licensed counselors who specialize in sexual assault counseling. 


\section{REFERENCES}

Abbey, A., Ross, L. T., McDuffie, D., \& McAuslan, P. (1996). Alcohol and dating risk factors for sexual assault among college women. Psychology of women quarterly, 20(1), 147169.

Akers, R. L. (1990). Criminology: Rational Choice, Deterrence, and Social Learning Theory in Criminology: The Path Not Taken. Journal of Criminal Law \& Criminology, 81653

American College Health Association. (2004). National College Health Assessment: Reference Group Executive Summary Spring 2004. Baltimore, MD: American College Health Association.

Ananiades, T. (2012). Penalty on the Field: Creating a NCAA Sexual Assault Policy. Vill. Sports \& Ent. LJ, 19, 463.

Armstrong, E. A., Hamilton, L., \& Sweeney, B. (2006). Sexual assault on campus: A multilevel, integrative approach to party rape. Social problems, 53(4), 483-499.

Aronowitz, T., Lambert, C. A., \& Davidoff, S. (2012). The Role of Rape Myth Acceptance in the Social Norms Regrading Sexual Behavior Among College Students. Journal of Community Health Nursing, 29(3), 173-182. doi:10.1080/07370016.2012.697852

Bachman, R., \& Schutt, R. (2012). Fundamentals of research in criminology and criminal justice. Thousand Oaks, CA: SAGE Publications, Inc.

Barnett, N. J., \& Feild, H. S. (1977). Sex differences in university students' attitudes towards rape. Journal of College Student Personnel, 2, 93-96.

Black, M. C., Basile, K. C., Breiding, M. J., Smith, S. G., Walters, M. L., Merrick, M. T., et al. (2011). National intimate partner and sexual violence survey. Atlanta, GA: Centers for Disease Control and Prevention, 75

Bondurant, B. (2001). University Women's Acknowledgment of Rape: Individual, situational, and social factors. Violence Against Women, 7(3), 294-314.

Burgess, A. W. (1983). Rape trauma syndrome. Behavioral Sciences \& the Law, 1(3), 97-113.

Boyle, K. M. (2015). Social Psychological Processes that Facilitate sexual assault within the fraternity part subculture. Sociology Compass, 9(5), 386-399.

Catalano, S., Smith, E., Snyder, H., \& Rand, M. (2009). Bureau of Justice Statistics selected findings: Female victims of violence. Washington, DC: US Department of Justice.

Chang, E. c., Jiachen, L., Fowler, E. E., Yu, E. A., Yu, T., Jilani, Z., Kahle, E. R., \& Hirsch, J. K. (2015). Sexual Assault and Depressive Symptoms in College Students: Do Psychological 
Clevenger, S.L. (2014). Treatment of victims in the criminal justice system. In T. Richards \& C. Marcum (Eds) Sexual Violence; Then and Now. Sage Publications, Thousand Oaks. CA. Needs Account for the Relationship?. Social Work, 60(3), 211-218.

Cohen, L. E., \& Felson, M. (1979). Social change and crime rate trends: A routine activity approach. American sociological review, 588-608.

Copenhaver, S., \& Grauerholz, E. (1991). Sexual victimization among sorority women: Exploring the link between sexual violence and institutional practices. Sex Roles, 24(1), $31-41$.

Durkin, K. F., Wolfe, T. W., \& Clark, G. A. (2005). College students and binge drinking: An evaluation of social learning theory. Sociological Spectrum, 25(3), 255-272.

Ellis, F., \& Hartley, R., D., \& Walsh, A. (2010). Research Methods in Criminal Justice and Criminology. Lanham, MD: Rowman \& Littlefield Publishers, Inc.

Fergusson, D. M., Horwood, L. J., \& Lynskey, M. T. (1997). Childhood sexual abuse adolescent sexual behaviors and sexual revictimization. Child Abuse \& Neglect, 21(8), 789-803.

Fisher, B. S., Cullen, F. T., \& Turner, M. G. (2000). The Sexual Victimization of College Women. Research Report.

Fisher, B. S., \& Daigle, L. S., \& Cullen, F. T. (2010). Unsafe in the Ivory Tower. Thousand Oaks, CA: SAGE Publications, Inc.

Franiuk, R. (2007). Discussing and Defining Sexual Assault: A Classroom Activity. College Teaching, 55(3), 104-107.

Franiuk, R. 2005. Sexual assault attitudes, beliefs, and experiences of students at the University of Wisconsin-Stevens Point. Manuscript in preparation.

Frohmann, L. (1991). Discrediting victims' allegations of sexual assault: Prosecutorial accounts of case rejections. Social problems, 38(2), 213-226.

Giacopassi, D. J., \& Dull, R. T. (1986). Gender and Racial Differences in the Acceptance of Rape Myths within a College Population. Sex roles, 15(1-2), 63-75.

Goodchilds, J. D., G. L. Zellman, P. B. John- son, and R. Giarrusso. 1988. Adolescents and their perceptions of sexual interactions. In Rape and sexual assault, vol. 2, ed. A. W. Burgess, 245-70. New York: Garland.

Greenfeld, L. A. (1997). Sex offenses and offenders: An analysis of data on rape and sexual assault (pp. i-39). Washington, DC: US Department of Justice, Office of Justice Programs. 
Hagan, F. E. (2010). Introduction to criminology: Theories, methods, and criminal behavior. Thousand Oaks: CA. Sage Publications, Inc.

Hanson, R. K. (1990). The psychological impact of sexual assault on women and children: A review. Annals of Sex Research, 3(2), 187-232.

Hanson, K. A., \& Gidycz, C. A. (1993). Evaluation of sexual assault prevention program. Journal of Consulting and Clinical Psychology, 61(6), 1046.

Hayes-Smith, R., \& Hayes-Smith, J. (2009). A website content analysis of women's resources and sexual assault literature on college campuses. Critical criminology, 17(2), 109-123.

Hunter, D. (2005). Campus safety: What every college student needs to know. Women in Business, 57(2), 16-17.

Illinois State University (2016). Fall 2016 University Factbook. Planning, Research, and Policy Analysis. Retrieved from: https://prpa.illinoisstate.edu/FactBook2016_Final.pdf

Jome, E. (2017). Illinois State University News. Illinois State university continues a strong enrollment trend. Retrieved from https://news.illinoisstate.edu/2017/09/illinois-stateuniversity-continues-strong-enrollment-trend/

Kahlor, L., \& Eastin, M. S. (2011). Television's role in the culture of violence toward women: A study of television viewing and the cultivation of rape myth acceptance in the United States. Journal of Broadcasting \& Electronic Media, 55(2), 215-231.

Kahn, A. S., Mathie, V. A., \& Torgler, C. (1994). Rape Scripts and Rape Acknowledgement. Psychological of Women Quarterly, 18, 53-66.

Kalof, L. (1993). Rape-supportive attitudes and sexual victimization experiences of sorority and nonsorority women. Sex Roles, 29(11-12), 767-780.

Kalof, L., \& Cargill, T. (1991). Fraternity and sorority membership and gender dominance attitudes. Sex Roles, 25, 419-425.

Konradi, A., \& Burger, T. (2000). Having the last word: An examination of rape survivors' participating in sentencing. Violence Against Women, 6, 351-395

Krebs, C. P., Lindquist, C. H., Warner, T. D., Fisher, B. S., \& Martin, S. L. (2007). The campus sexual assault (CSA) study: Final report. Washington, DC: National Institute of Justice, US Department of Justice.

Lee, M. J., Hust, S., Zhang, L., \& Zhang, Y. (2011). Effects of violence against women in popular crime dramas on viewers' attitudes related to sexual violence. Mass Communication \& Society, 14(1), 25-44. doi:10.1080/5205430903531440 
Legislative Information System (2016). Illinois General Assembly. Retrieved from http://www.ilga.gov/legislation/ilcs/fulltext.asp?DocName=072000050K11-1.20.

Lilly, R., J., \& Cullen, F., T., \& Ball, R., A. (2015). Criminological Theory: Context and Consequences. Thousand Oaks, CA: SAGE Publications, Inc.

Loiselle, M., Brower, A. M., \& Thompson, M. (2007). Campus violence. Journal of American College Health, 55(5), 261-319.

Martin, P. Y., \& Hummer, R. A. (1989). Fraternities and rape on campus. Gender \& Society, $3(4), 457-473$.

Maxfield, M., \& Babbie, E. (2005). Research methods for criminal justice and criminology. Belmont CA: Wadsworth Thomson Learning.

Mead, G. H., \& Mind, H. (1934). Self and society. Chicago: University of Chicago, 173-175.

McCord, D. (1984). The admissibility of expert testimony regarding rape trauma syndrome in rape prosecutions. BCL Rev., 26, 1143.

Minow, J. C., \& Einolf, C. J. (2009). Sorority participation and sexual assault risk. Violence Against Women, 15(7), 835-851.

Mohler-Kuo, M., Dowdall, G., Koss, M., \& Wechsler, H. (2004). Correlates of rape while intoxicated in a national sample of college women, Journal Of Studies on Alcohol, 65(1), $37-45$.

Morczek, A. (2015). The Synergistic Connection Between Sexual Violence and Rape Culture. Sexual Assault Report, 18(4), 49-60.

Mustaine, E. E., \& Tewksbury, R. (2002). Sexual assault of college women: A feminist interpretation of a routine activities analysis. Criminal Justice Review, 27(1), 89-123.

Navarro, J. \& Clevenger, S. (2017) Investigating students' Experiences with Sexual Victimization at a Rural Institution.

Newcombe, P. A., Van Den Eynde, J., Hafner, D., \& Jolly, L. (2008). Attributions of responsibility for rape: Differences across familiarity of situation, gender, and acceptance of rape myths. Journal of Applied Social Psychology, 38(7), 1736-1754.

Parent, C. M. (2002). Personal fouls: How sexual assault by football players is exposing universities to title IX liability. Fordham Intell. Prop. Media \& Ent. LJ, 13, 617.

RAINN (2016). Programs and Expertise. Retrieved from https://www.rainn.org/programs-andexpertise 


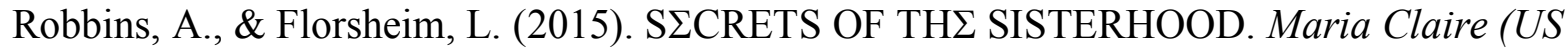
Edition), 22(8), 146.

Romero-Sánchez, M., \& Megías, J. L. (2015). How do college students talk about sexual assault? Journal of Gender Studies, 24(6), 644-659.

Sampson, R. (2002). “Acquaintance Rape of College Students." Problem- Priented Guides for Police Series, No. 17. Washington, DC: U.S. Department of Justice, Office of Community Oriented Policing Services.

Schewe, P., Riger, S., Howard, A., Staggs, S., \& Mason, G. (2006). Factors Associated with Domestic Violence and Sexual Assault Victimization. Journal of Family Violence, 21(7), 469-475. doi:10.1007/s10896-006-9042-2

Schwartz, M. D., \& Pitts, V. L. (1995). Exploring a feminist routine activities approach to explaining sexual assault. Justice Quarterly, 12, 9-31.

Simonson, K., \& Subich, L. M. (1999). Rape perceptions as a function of gender-role traditionality and victim-perpetrator association. Sex Roles, 40, 617-634.

Sinozich, S., \& Langton, L. (2014). Rape and Sexual Assault Victimization Among College-Age Females, 1995-2013. Report NCJ248471. Washington, DC: US Department of Justice. Bureau of Justice Statistics.

Smith, M., Wilkes, N., \& Bouffard, L. A. (2016). Rape myth adherence among campus law enforcement officers. Criminal Justice and Behavior, 43(4), 539-556.

Szymanski, L. A., Devlin, A. S., Chrisler, J. C., \& Vyse, S. A. (1993). Gender role and attitudes toward rape in male and female college students. Sex Roles, 29(1), 37-57.

Tongco, M. D. C. (2007). Purposive sampling as a tool for informant selection. Ethnobotany Research and Applications, 5, 147-158.

Trebon, K. M. (2007). There is No I in Team: The Commission of Group Sexual Assault by Collegiate and Professional Athletes. DePaul J. Sports L. \& Contemp. Probs., 4, 65.

Truman, L. T., \& Morgan E. R. (2016). The U.S. Department of Justice, Office of Justice Programs, Bureau of Justice Statistics. Retrieved from https://www.bjs.gov/content/pub/pdf/cv15.pdf

Ullman, S. E., Karabatsos, G., \& Koss, M.P. (1999). Alcohol and sexual assault in a national sample of college women. Journal of Interpersonal Violence.

Ullman, S. E., Relyea, M., Peter-Hagene, L., \& Vasquez, A. L. (2013). Trauma histories, substance use coping, PTSD, and problem substance use among sexual assault victims. Addictive behaviors, 38(6), 2219-2223. 
Vance, K., Sutter, M., Perrin, P. B., \& Heesacker, M. (2015). The Media's Sexual Objectification of Women, Rape Myth Acceptance, and Interpersonal Violence. Journal of Aggression, Maltreatment \& Trauma, 24(5), 569-587. doi:10.1080/10926771.2015.1029179

Weir, T., \& Brady, E. (2003). In sexual assault cases, athletes usually walk. USA Today.

White House Task Force. (2014). Intersection of Title IX and the Clery Act. Retrieved from https://www.justice.gov/ovw/page/file/910306/download

Wilcox, P., Jordan, C. E., \& Prichard, A. J. (2007) A multidimensional examination of campus safety: Victimization, perceptions of danger, worry about crime, and precautionary behavior among college women in the post-Clery era. Crime \& Delinquency, 53(2), 219254. doi: $10.1177 / 0097700405283664$. 


\title{
PLEASE
}

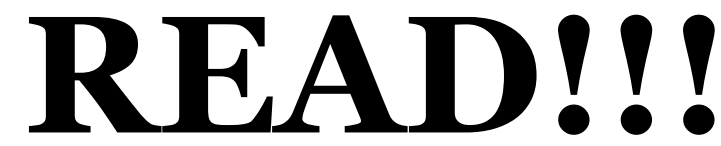

\section{Volunteer research opportunity}

\section{for students!}

A criminal justice professor at Illinois State University invites volunteers to participate in a research study. She is interested in learning about the perceptions of sexual assault and services available on campus. Information gathered from your participation will help the researcher determine and design programming and education suggestions for campus.

Participation in this study is completely voluntary. All volunteers must be 18 years of age or older. Participants must be current students of Illinois State University or alumni who have graduated within only 2 years. Any information provided by participants will be kept confidential. Thank you for your time and consideration of this matter. Information obtained from this study will be used for academic purposes and also to potentially impact programming for survivors in the future.

If you are interested in participating or have any questions, please contact the researcher directly:

\author{
Dr. Shelly Clevenger \\ Criminal Justice Sciences Professor \\ 413 Schroeder Hall \\ 724-***_***** \\ s******@ilstu.edu
Brittany L. Acquaviva
Graduate student
438 Schroeder Hall
Normal, IL 61761
630-***_****
b $* * * * * * @$ ilstu.edu




\section{APPENDIX B: VOLUNTARY INFORMED CONSENT FORM}

I would like to invite you to participant in a research study. I ask that you please review the following information so that you can make an informed decision in regards to your participation in this project. If you choose to participate, please keep in mind that I would like for you to ask any questions, at any time, about this study, my intentions, and your role as a participant.

The purpose of this study is to learn and understand about the perceptions regarding sexual assault and services for survivors on Illinois State University's campus. Specifically, what your opinion is regarding sexual assault and the services offered on campus. Interviews are expected to take about 30 minutes to two hours of the participants' time. However, this is only an estimate, and interviews could be shorter or longer. All participants must be 18 years of age or older. Participants must also be currently enrolled students at Illinois State University or individuals who have graduated within nor more than 2 years.

Your participation in the study will not have any effect on your enrolment with Illinois State University. This project is in no way affiliated with the programming or administration of this organization. In addition to this, your decision not to participate will have no negative consequences as well. Participation in this study is completely voluntary. You will receive a copy of a signed consent form. One will also be kept on file with the researcher at Illinois State University in a locked drawer were we will be the only ones who have access to these forms with identifying information on them.

During the interviewing process, some questions will contain matters of a sensitive nature. If at any time you feel you cannot continue with the interview or wish not to answer certain questions, your requests will be granted by the interviewer. If you wish to withdraw at any time, all information will be destroyed. You will not experience any negative effects for doing so. Interview sessions will consider the comfort level of the participants and respect each participant's wishes. Each participant has the option to request that their interview not be recorded.

Interviews will be coded with identification numbers and the use of pseudonyms will be used in write ups of results. Participants names associated with their interviews will be on one master list that will be locked in a drawer so no one other than the researchers will be able to access it. This will help to grant confidentiality. Information given to me will be stored securely and used for research purposes in academia and to potentially assist in revamping of educational programs administered to students at Illinois State University in regards to sexual assault. Your name will not be disclosed in association with your information given during the interview. However, I will be required to report any information such as: intent to harm oneself or another person, intent to engage in future criminality and if you have been victimized as I am a mandated reporter.

There is a possibility that the interview can cause emotional distress as you will be discussing sensitive material. Information for Stepping Stones and counseling services oncampus at the Student Counseling center will be provided to you after the interview. This will include the local center as well as the 24-hour hotline. All services available are free of charge to you.

With your permission, interviews will be recorded however, you have the option to deny the use of a recorder with no negative consequences. As soon as interviews are transcribed the recordings will be destroyed. I will use quotes in my write up of my research, but no identifying 
information will be used in future publications as well as the names of individuals will never be used. This will be done to ensure confidentiality to participants. To protect the participants, information will be stored under lock and key where no one other than the researchers will have access to it.

If you are willing to participate please sign and date the attached form. If you do not wish to proceed with participation in this study, I would like to thank you for your time and consideration of this matter.

\section{Voluntary Consent Form}

After reviewing the following information provided by the researcher, I volunteer to participate in this research study. I understand that information I provide will be kept confidential and no identifying information will be used. I understand that my participation is completely voluntary and that I may withdraw from participation in this study at any time, without any negative repercussions.

Name (Please Print)

Signature

Date

I hereby certify that I have explained to the participant the nature of this study, potential benefits, and possible risks associated with participation, and have given the opportunity for questions to be asked and answered in regard to this study.

Signed: Date:

Contact information:

Dr. Shelly Clevenger

Illinois State University

413 Schroeder Hall

Normal, IL 61761

$724-* * *-* * * *$

s******@ilstu.edu

Brittany L. Acquaviva

Illinois State University

438 Schroeder Hall

Normal, IL 61761

$630-* * *-* * * *$

b******@ilstu.edu

Please direct questions about research participants' rights and/or a research related injury or adverse effects to:

The Research Ethics \& Compliance Office

(309) 438-2529

rec@ilstu.edu 


\section{APPENDIX C: DEBRIEFING FORM}

Thank you for participating in this research to assist in the understanding of the perspectives and experiences of those who survive sexual assault. Your feedback is valuable and greatly appreciated. If you have any questions or concerns about the research, please do not hesitate to contact me directly:

Dr. Shelly Clevenger

Illinois State University

413 Schroeder Hall

Normal, IL 61761

$724-* * *$-*****

$\mathrm{s} * * * * * * @$ ilstu.edu

\section{Brittany L. Acquaviva}

Illinois State University

438 Schroeder Hall

Normal, IL 61761

$630-* * *+* * * *$

b******@ilstu.edu

If after participating in this research, you are experiencing some emotional distress, such as feelings of high anxiety, thoughts of harming yourself of others and/or you feel that you need to talk with someone, below is the toll free number of your local ICASA Center. Services are available 24 hours a day, free of charge. (I will list the local ICASA center information, depending on location where research is currently being conducted). Information on ICASA's centers and services can also be viewed on the Internet at www.icasa.org.

Listed below are all ICASA centers within Illinois that individuals who are not on campus may utilize as well as individuals whose primary address is not on campus. It is stressed that all centers are free of charge to individuals who wish to access recourses from these locations.

Student Counseling Services

Illinois State University

Room 320 in the Student Services Building

24 hrs. 309-438-3655

NORTH ARLINGTON HEIGHTS

Northwest ICASA

24 hrs. 888-802-8890

AURORA

Mutual Ground, Inc.

24 hrs. 630-897-8383

\section{CHICAGO HEIGHTS}


YWCA

Metropolitan Chicago South Suburban Center Sexual Violence and Support Services

24 hrs. 708-748-5672

DEKALB

Safe Passage, Inc.

24 hrs. 815-756-5228

ELGIN

Community Crisis Center

24 hrs. 847-697-2380

GALENA

Riverview Center

24 hrs. 888-707-8155

Mount Carroll Riverview Center

Carroll County

24 hrs. 877-273-7772

Dubuque, Iowa Riverview Center Dubuque County

24 hrs. 888-557-0310

Manchester, Iowa

Riverview Center

24 hrs. 888-707-8155

GLENDALE HEIGHTS

YWCA Metropolitan Chicago

Patterson and McDaniel Family Center

24 hrs. 630-971-3927

GURNEE

Zacharias Sexual Abuse Center

24 hrs. 847-872-7799

HICKORY HILLS

The Pillars Community Services

24 hrs. 708-482-9600

Berwyn

The C.A.R.E. Center

24 hrs. 708-482-9600

JOLIET

Sexual Assault Service Center 
Guardian Angel Community Services

24 hrs. 815-730-8984

KANKAKEE

Kankakee County Center Against Sexual Assault

24 hrs. 815-932-3322

Watseka

Iroquois Sexual Assault Services.

24 hrs. 815-432-0420

MCHENRY

Voice Sexual Assault Program

24 hrs. 800-892-8900

PRINCETON

Freedom House, Inc.

24 hrs. 800-474-6031

QUAD CITIES

Rape/Sexual Assault Program Family Resources, Inc.

24 hrs. 309-797-1777

\section{ROCKFORD}

Rockford Sexual Assault Counseling, Inc.

24 hrs. 815-636-9811

Belvidere Rockford Sexual Assault Counseling, Inc.

24 hrs. 815-636-9811

Rochelle Rockford Sexual Assault Counseling, Inc.

24 hrs. 815-636-9811

Rockford Prevention Office

24 hrs. 815-636-9811

STERLING

YWCA of the Sauk Valley

24 hrs. 815-626-7277

Dixon

YWCA of the Sauk Valley

24 hrs. 815-288-1011

STREATOR

24 hrs. 800-892-3375 
Pontiac

24 hrs. 800-892-3375

Outreach Office: Ottawa

24 hrs. 800-892-3375

CHICAGO

Chicago Citywide Toll free 24-Hour Hotline

$1-888-293-2080$

Stepping Stones Sexual Assault Services

YWCA of McLean County

24 hrs. 309-827-4005

CHARLESTON/MATTOON

Sexual Assault Counseling \& Information Service

24 hrs. 888-345-2846

Robinson Counseling \& Information for Sexual Assault/Abuse

24 hrs. 866-288-4888

DANVILLE

Vermillion County Rape Crisis Center

24 hrs. 866-617-3224

DECATUR

Growing Strong Sexual Assault Center

24 hrs. 217-428-0770

MACOMB

Western Illinois Regional Council/Community Action Agency Victim Services

24 hrs. 309-837-5555

\section{PEORIA}

The Center for the Prevention of Abuse Sexual Assault Services

24 hrs. 309-691-4111 or 309-691-0551

QUINCY

Quanada Sexual Assault Program 24 hrs. 800-369-2287

Pittsfield

Pike County Satellite Office

24 hrs 800-369-2287

SPRINGFIELD 
Prairie Center Against Sexual Assault

24 hrs. 217-753-8081

Jacksonville

Prairie Center Against Sexual Assault

24 hrs. 217-753-8081

URBANA/CHAMPAIGN

Rape, Advocacy, Counseling and Education Services

24 hrs. 217-384-4444 or 877-236-3727

BELLEVILLE

Call For Help, Inc. Sexual Assault Victims Care Unit

24 hrs. 618-397-0975

East St. Louis

Call For Help, Inc. Sexual Assault Victims Care Unit

24 hrs. 618-397-0975

Satellite Office: Granite City

Call For Help, Inc., Sexual Assault Victims Care Unit

24 hrs. 618-397-0975

CARBONDALE

Rape Crisis Services of The Women's Center, Inc.

24 hrs. 618-529-2324 or 800-334-2094

Marion Rape Crisis Services of The Women's Center, Inc.

24 hrs. 800-334-2094

VANDALIA

Sexual Assault and Family Emergencies

24 hrs. 800-625-1414

Centralia Sexual Assault and Family Emergencies

24 hrs. 800-625-1414

Effingham Sexual Assault and Family Emergencies

24 hrs. 800-625-1414 


\section{APPENDIX D: INTERVIEW GUIDE}

What gender do you most identify with?

What is your age?

What is your current class standing at ISU?

(Freshman, Sophomore, Junior, Senior, Graduate, Alumni)

Are you affiliated with a fraternity or sorority on campus?

What is your major?

Where do you currently live? NOT APPLICAABLE FOR ALUMNI

(Dorms, off campus, fraternity/sorority house, other)

What race or ethnicity do you most identity with?

How would you define sexual assault?

How would you define consent?

(verbal only, can it be taken away after saying yes)

pressures to not say no

$\rightarrow$ questions about consent in high school

$\rightarrow$ did your parents talk to you about consent?

What do you believe the difference between a completed rape is and an attempted rape is, if there is any?

(should they be handled differently)

(What acts are considered completed rape and attempted rape) difference with SA, rape

(are they weighted differently? Do you think one is more believable than the other?)

In your own worlds describe what a sexual assault looks like?

(What comes to mind?)

(what does the victim look like, offender look like, race)

Are younger students more likely to becoming sexual assaulted?

What do you know about sexual assault?

-How familiar are you with sexual assault

-Trial process

-Reporting

-Symptoms

-Victims

-Offenders

-TV shows 
Where does your knowledge of sexual assault come from?

Are you familiar with any rape myths? If so, what are some of the most frequently used rape myths you have heard?

-first are you familiar with some?

-what are some that you have heard of the most?

Can you name any sexual assault cases that have been in the media recently?

What is your opinion on the case?

What do you think leads to someone sexually assaulting another individual on college campuses?

What is your opinion about sexual assault at Illinois State University?

-Do you believe it to be an issue? Please explain.

Can you please describe any training you received from Illinois State University on sexual assault?

-When was this training?

-Did you find it valuable? Why or why not?

Can you please describe the services that you are aware of that Illinois State University offers victims of sexual assault?

Please describe what you believe would be a good strategy for Illinois State to use to better educate students about sexual assault. 


\section{ISU Perceptions Thesis Codebook}

Using ATLAS.ti version 8.1.3 (522)

\section{DEMOGRAPHIC QUESTIONS:}

\section{Pseudonym:}

Interviewee chose their own name that they wanted to be referred to. If they waived that option that researcher picked a random name for them to ensure confidentiality.

\section{Initials of Interviewer:}

BLA $=$ Brittany L. Acquaviva

SLC $=$ Dr. Shelly L. Clevenger

\section{Gender:}

Female $=\mathrm{F}$

Male $=\mathrm{M}$

Other $=$ Interviewees are able to answer what gender they most identify with for the

current study no one answered out of the dichotomous categories Male or Female.

Age:

Interviewee states their age.

Class standing:

Undergraduate student-

$$
\begin{aligned}
& \mathrm{Sn}=\text { Senior } \\
& \text { J= Junior } \\
& \mathrm{S}=\text { Sophomore } \\
& \mathrm{F}=\text { Freshman }
\end{aligned}
$$

Graduate student

Alumni student (within 2 years of graduation)

Affiliation with Greek Life:

$Y e s=$ They had been affiliated, not necessarily initiated

No - They had never been involved with Greek Life or apart of any of the organizations

* If a participant was affiliated with Greek Life and then dropped out they were still marked as yes as they had been involved for a partial amount of time to separate them from those individuals who had never experienced any Greek life while attending Illinois State University.

Major:

Interviewee stated their acquired major (if Alumni) or in progress major at Illinois State University 


\section{Living Location:}

On-campus $=$ Dorms $($ Tri-Towers, Waterson, Manchester and Hewett), Cardinal Court

Off-campus $=$ Apartments (with or without university association)

Sorority or Fraternity House

Race/Ethnicity:

Interviewee stated the race/ethnicity they most identify with. There were no categories to give participants the freedom to pick their race without any confines.

\section{Themes:}

\section{CONSCENT EXPECATIONS}

Code group title: Consent Expectations

Code: Can take away consent anytime

Conceptualization:

Any response involving the acceptance of being able to take away consent even if it was initially given during a sexual encounter. Any response involving the right to take away consent.

Code: Cannot take away consent once its given

Conceptualization:

Any response related to the acceptance of an individual not being able to take away consent once it was initially given.

Code: No consent needed if you are in a relationship

Conceptualization:

Any response on the topic of not needing consent if two people are in a relationship. Any response on the topic of individuals not considering sexual assault occurring in a relationship if they had sex while intoxicated, if they initially did not want to engage in sexual activity and did, or having no expectation to consent or have partner consent to sexual activity.

Code: No pressure to consent

Conceptualization:

Any response stating there is no pressure in college to consent to sexual activity even if you do not want to.

Code: Pressure to consent

Conceptualization:

Responses explaining a pressure existing on college campuses to consent to sexual activity. Responses explaining begging or nagging from another individual to engage in any sexual activity. And responses involving the idea of consenting to sexual activity to get another person to like them more or to keep a person liking them. 
Code: Verbal and non-verbal consent

Conceptualization:

Responses stating that non-verbal and verbal consent can be utilized to express consent to sexual activity.

Code: Verbal consent only

Conceptualization:

Responses explaining that only verbal consent should be exercised to give consent to sexual activity.

\section{SEXUAL ASAULT AND CONSENT EDUCAITON PRIOR TO ATTENDING ISU}

Code group title: $\mathrm{SA}+$ Consent Education

Code: High school education on SA \& consent

Conceptualization:

Responses stating that interviewees had received high school education on sexual assault or consent.

The researcher made notes on the degree of the education (i.e. if it was generic education, how long was it, was it taken seriously).

Code: No high school education

Conceptualization:

Responses explaining that they did not receive any education on sexual assault or consent while in high school.

Code: No talk with parents

Conceptualization:

Responses explaining that interviewees did not have a talk about sexual assault or consent with their parents.

Code: Talk about SA \& Consent with parents

Conceptualization:

Responses explaining interviewees having a talk with their parents on sexual assault and consent.

The researcher noted when the talk took place (before college, during high school, during college) and what the talk consisted of (measuring its degree).

Code: Parent education WAS valuable

Conceptualization:

Responses stating that the talk that interviewees had on sexual assault and consent with their parents was valuable. 
Code: Education would have been valuable

Conceptualization:

Responses involving those who had not received high school education or parental education expressing that either education would have been valuable.

The researcher made note on which if of the two would have been more valuable. If specified by the interviewee.

\section{DEFINING COMPLETED RAPE VERSES ATTEMPTED RAPE}

Code group title: Completed rape v. Attempted rape

Code: ACTUAL rape v. attempted rape

Conceptualization:

Responses explaining the difference between what a completed rape is and what an attempted rape is. Responses listing criteria that would need to be met in order to be a victim of a completed rape and criteria that would need to be met to be a victim of an attempted rape.

Also, responses where interviewees changed the wording of the term "completed rape" to actual rape were added into this code.

Code: less of a victim if only attempted rape

Conceptualization:

Responses expressing how victims of attempted rape may be stigmatized more than victims of completed rape.

Responses involving explanation of why victims of attempted rape might be seen as less of a victim or taken less seriously by peers or authorities.

Code: no difference between the two (intent)

Conceptualization:

Responses stating that a completed rape and an attempted rape should not be handled differently legally because of the intent being the same between the two assaults.

Ex.) Comparing no difference between attempted murder and murder together with attempted rape and completed rape.

\section{WHAT SEXUAL ASSAULT LOOKS LIKE}

Code group title: What sexual assault looks like

Code: SA individuals were white 


\section{Conceptualization:}

When asked what sexual assault looks like and what first comes to mind interviewees explain a scenario where the victim and the offender were identified as white.

\section{Code: SA offender was a male}

Conceptualization:

When asked what sexual assault looks like and what first comes to mind interviewees explain a scenario where the offender of the sexual assault was a man.

Code: SA victim was female

Conceptualization:

When asked what sexual assault looks like and what first comes to mind interviewees explain a scenario where the victim of the sexual assault was a female.

\section{COMMONLY HEARD RAPE MYTHS}

Code group title: Commonly heard rape myths

Code: "She wanted it"- statements

Conceptualization:

Responses from interviewees related to the idea that a victim of sexual assault "wanted their victimization".

Code: Do not know of rape myths

Conceptualization:

Participants were unfamiliar with the term rape myths.

Code: Do not know of victim-blaming

Conceptualization:

Participants were unfamiliar with the term victim-blaming.

Code: R.M. alcohol was involved so NOT SA

Conceptualization:

Participants knowing the rape myth of when alcohol is involved, and any sexual activity occurs people do not see that as a sexual assault.

This code was noted when asked about any known rape myths as well as throughout the interview if presented.

Code: R.M. already consent once before

Conceptualization:

Participants knowing the rape myth of if someone already consented then the next time the parties have sexual intercourse the consent is assumed/expected. 
This code was noted when asked about any known rape myths as well as throughout the interview if presented.

Code: R.M. men cannot be victims

Conceptualization:

Participants knowing the rape myth of men not being victims of sexual assault.

This code was noted when asked about any known rape myths as well as throughout the interview if presented.

Code: R.M. she just regretted it in the morning

Conceptualization:

Participants knowing the rape myth of a women who had been out drinking the night before and waking up and saying she was sexually assault because she regretted having sex that night.

This code was noted when asked about any known rape myths as well as throughout the interview if presented.

Code: R.M. what she was wearing

Conceptualization:

Participants knowing the rape myth of because of what a woman was wearing she was sexually assaulted and sometimes wanted her victimization.

This code was noted when asked about any known rape myths as well as throughout the interview if presented.

\section{WHY SEXUAL ASSAULT OCCURS ON ISU'S CAMPUS}

Code group title: WHY SA on college

Code: "College scene" = risk for $S A$

Conceptualization:

Responses stating the "college scene" being why sexual assault occurs on campus.

Code: alcohol consumption

Conceptualization:

Responses stating the presence of alcohol being why sexual assault occurs on campus or promoting sexual assault on campus.

The researcher also used this code whenever alcohol was referred to when talking about sexual assault in general.

Code: Entitlement

Conceptualization: 
Responses stating that the sense of entitlement being why sexual assault occurs on campus or promoting sexual assault on campus.

The researcher also used this code whenever entitlement was referred to when talking about sexual assault throughout the interview.

\section{Code: Greek Life}

Conceptualization:

Responses stating that Greek Life was the reason for why sexual assault occurs on campus.

The researcher also used this code whenever Greek Life was referred to when talking about sexual assault throughout the interview.

Code: Just want to fit in

Conceptualization:

Responses stating that the sense wanting to fit in being why sexual assault occurs on campus.

The researcher also used this code whenever the idea of wanting to fit in was referred to when talking about sexual assault throughout the interview.

\section{Code: Lack of education}

Conceptualization:

Responses stating that the lack of education on sexual assault and consent was why sexual assault occurs on campus.

The researcher also used this code whenever the lack of education was referred to when talking about sexual assault throughout the interview.

Code: Mentally ill

Conceptualization:

Responses stating that mental illness was why sexual assault occurs on campus or promoting sexual assault on campus and in general.

\section{Code: Power}

Conceptualization:

Responses stating that individuals wanting power being why sexual assault occurs on campus.

The researcher also used this code whenever the sense of power some individuals may desire was mentioned when talking about sexual assault throughout the interview.

Code: Rape culture

Conceptualization: 
Responses stating that the acceptance of rape culture was why sexual assault occurs on campus.

\section{THE PREVELANCE OF SEXUAL ASSAUTL ON CAMPUS}

Code group title: Sexual Assault at ISU

Code: Do not know of any SA incident as ISU

Conceptualization:

Interviewees reported not knowing of any incident of sexual assault at Illinois State University.

Code: Know of SA incident at ISU

Conceptualization:

Interviewees shared their own victimization on campus while attending Illinois State University or reported knowing of an incident of sexual assault on campus at Illinois State University.

Code: Know of SA in general

Conceptualization:

Interviewees reported knowing of a sexual assault incident outside of Illinois State University.

Code: $S A$ is an issue at ISU

Conceptualization:

Participants stating that they believed sexual assault was an issue on campus.

Code: SA is not an issue at ISU

Conceptualization:

Participants stating that they believed sexual assault was not an issue on campus.

\section{TRAINING ON SEXUAL ASSAULT AND CONSENT WHILE ATTENDING ISU}

Code group title: Training at ISU on SA + Consent

Code: No ISU training/Cannot remember any training

Conceptualization:

Responses involving participants not receiving any training or not being able to remember any training on sexual assault or consent given to them by Illinois State University.

Code: Received training from ISU

Conceptualization: 
Participants responding that they had received training on sexual assault and consent from Illinois State University as a student.

The research noted the participants who stated that they only had received training on sexual assault and consent because it was a requirement of their employment with the university (being a graduate assistant, working for PATH, working for the bone, working for the counseling center).

Code: Received training outside of ISU

Conceptualization:

Participants responding that they had received training on sexual assault and consent from an outside source that was not Illinois State University.

Code: Training was effective

Conceptualization:

Responses stating that the training on sexual assault and consent from Illinois State University was effective and beneficial.

Responses explaining that interviewees had learned something new that they did not know previously because of the training.

Code: Training was ineffective

Conceptualization:

Responses explaining that the training on sexual assault and consent from Illinois State University was ineffective and not beneficial.

\section{KNOLWEDGE ON SERVICES THAT ISU OFFERED VICTIMS OF SEXUAL ASSAULT}

Code group title: Services ISU offers to SA victims

Code: Do not know of any services

Conceptualization:

Participants responding that they did not know of any services their campus offered victims of sexual assault.

Participants responding that they knew of services but were unable to list any.

Participants who were able to only list Student Counseling or Student Health Services as an assumed resource that victims could utilize.

Code: Know of services on campus

Conceptualization:

Participants who knew of other resources outside of Student Counseling or Student Health Services that their campus offered victims of sexual assault. 
Code: Student counseling services

Conceptualization:

Responses exhibiting any knowledge of Student Counseling Services or the mention of the Student Health Services building offering counseling somewhere inside for students at the university.

\section{UNEXPECTED MISELLANIOUS THEMES}

\section{"Nice Guy" Offender:}

Conceptualization:

Responses showing the presence of hesitancy to place blame on certain individuals guilty of sexual assault who are seen as a "good guy".

The hesitancy to label someone an offender of sexual assault against a woman if they are a known activist, feminist, and popular.

Advice for better SA education for ISU

Conceptualization:

Participants offered their opinion and advice on what they would like to see change in the education they receive on sexual assault and consent.

\section{Can't consent if blatantly drunk}

Conceptualization:

Participants explaining that sexual activity while intoxicated is not sexual assault.

However, as soon as someone is "blatantly" intoxicated (falling over, cannot form sentences, eyes closed, limp body, concerned friends) and sexual activity occurs then that is seen as sexual assault.

\section{$S A$ in relationships}

Conceptualization:

Responses stating that sexual assault does not occur in intimate relationships.

SA v. Rape

Conceptualization:

Participants explaining the difference they believe there is between a sexual assault and a rape.

Responses including differentiating rape and sexual assault as two different entities with different criteria required in order to be a victim of either assault. 